NBER WORKING PAPER SERIES

\title{
E-ZTAX: TAX SALIENCE AND TAX RATES
}

\author{
Amy Finkelstein \\ Working Paper 12924 \\ http://www.nber.org/papers/w12924 \\ NATIONAL BUREAU OF ECONOMIC RESEARCH \\ 1050 Massachusetts Avenue \\ Cambridge, MA 02138 \\ February 2007
}

The views expressed herein are those of the author(s) and do not necessarily reflect the views of the National Bureau of Economic Research.

(C) 2007 by Amy Finkelstein. All rights reserved. Short sections of text, not to exceed two paragraphs, may be quoted without explicit permission provided that full credit, including $\odot$ notice, is given to the source. 
E-ZTax: Tax Salience and Tax Rates

Amy Finkelstein

NBER Working Paper No. 12924

February 2007

JEL No. H11,H71,R48

\begin{abstract}
$\underline{\text { ABSTRACT }}$
This paper tests the hypothesis that the salience of a tax system affects equilibrium tax rates. To do this, I analyze how toll rates change after toll facilities adopt electronic toll collection. Unlike manual toll collection, in which the driver must hand over cash at the toll collection plaza, electronic toll collection automatically debits the toll amount as the car drives through the toll plaza, thereby plausibly decreasing the salience of the toll. I find robust evidence that toll rates increase following the adoption of electronic toll collection. My estimates suggest that, in steady state, toll rates are 20 to 40 percent higher than they would have been without electronic toll collection. Consistent with the hypothesis that decreased tax salience is responsible for the increase in toll rates, I also find evidence that the short run elasticity of driving with respect to the actual toll declines (in absolute value) following the adoption of electronic toll collection. I consider a variety of alternative explanations for these results and conclude that these are unlikely to be able to explain the findings.
\end{abstract}

\author{
Amy Finkelstein \\ Department of Economics \\ MIT E52-350 \\ 50 Memorial Drive \\ Cambridge MA 02142 \\ and NBER \\ afink@mit.edu
}




\section{Introduction}

For every dollar of revenue raised by the US income tax system, taxpayers incur about 10 cents in private compliance costs associated with record keeping and tax filing (Slemrod 1996). These compliance costs impose a dead-weight burden on society. Yet policies that would reduce these costs are frequently opposed by policy-makers and economists who believe that compliance costs play an important role in keeping taxes visible and salient to the electorate, who then serve as an important check on attempts to raise the scale of government activity beyond what an informed citizenry would want.

For example, Milton Friedman has publicly lamented his inadvertent contribution to the growth of government by encouraging the introduction of the visibility-reducing Federal income tax withholding system during the Second World War (Friedman and Friedman, 1998 p.123). More recently, in 2005, The President's Advisory Panel on Federal Tax Reform failed to reach consensus on whether to replace part of the existing income tax system with a value-added tax (VAT) in part because of concerns about how the lower visibility of a VAT would affect the size of government. As the Advisory Panel noted in its report:

"[Some] Panel Members were unwilling to support the [VAT] proposal given the lack of conclusive empirical evidence on the impact of a VAT on the growth of government. Others were more confident that voters could be relied on to understand the amount of tax being paid through a VAT, in part because the proposal studied by the Panel would require the VAT to be separately stated on each sales receipt provided to consumers. These members of the Panel envisioned that voters would appropriately control growth in the size of the federal government through the electoral process." (The President's Advisory Panel on Federal Tax Reform 2005, p.203-204).

The idea that a less visible tax system may fuel the growth of government can be traced back at least to John Stuart Mill's 1848 Principles of Political Economy. It has its modern roots in the public choice tradition of "fiscal illusion". In a series of influential books and articles, James Buchanan and co-authors have argued that citizens systematically under-estimate the tax price of public sector activities, and that government in turn exploits this misperception to allow it to reach a size that is larger than an informed citizenry would want. The extent of the tax misperception - and thus the size of government - is in turn affected by the choice of tax instruments, with more complicated and less visible taxes exacerbating the 
extent of fiscal illusion and thereby increasing the size of the government (e.g. Buchanan 1967, Buchanan and Wagner 1977, Brennan and Buchanan, 1980).

Empirical evidence of the impact of tax salience on tax rates, however, has proved extremely elusive. Most of the evidence comes from cross sectional studies of the relationship between the size of government and the visibility of the tax system, where the direction of causality is far from clear (Oates 1988, Dollery and Worthington, 1996). Moreover, the sign of any effect of tax salience on tax rates is theoretically ambiguous. The link between tax salience and tax rates is therefore an open empirical question.

In this paper, I examine the relationship between tax salience and tax rates empirically by studying the impact of the adoption of electronic toll collection (hereafter, "ETC") on toll rates. Electronic toll collection systems - such as the eponymous E-ZPass in the Northeastern United States, I-Pass in Illinois, or Fast-Trak in California - allow automatic deduction of the toll as the car drives through a toll plaza. Because the driver need no longer actively count out and hand over cash for the toll, the toll rate is arguably less visible under an electronic collection system. Different toll facilities in the United States have adopted ETC at different points in time over the last several decades, and some have not yet adopted it. As a result, I am able to examine within toll-facility changes in toll rates associated with the introduction of ETC. To do so, I collected a new data set on the history of toll rates and the date (if any) of installation of ETC for 123 toll facilities in the United States. Where available, I also collected annual, facility-level data on toll traffic, toll revenue, and the share of each that is paid by electronic toll collection.

I find robust evidence that toll rates increase after the adoption of electronic toll collection. My estimates suggest that when the proportion of tolls paid using ETC has diffused to its steady state level of about 60 percent, toll rates are 20 to 40 percent higher than they would have been under a fully manual toll collection system. I also find evidence that the short run elasticity of driving with respect to the actual toll declines (in absolute value) with the adoption of electronic toll collection. This is consistent with the conjecture that ETC increases the equilibrium toll rate by decreasing its salience. 
Of course, ETC affects more than just the visibility of tolls. In the final section of the paper, I consider a wide range of alternative explanations for the rise in tolls under ETC. Perhaps the most a priori compelling alternative explanation is that ETC reduces the compliance (i.e. time) costs to drivers of paying tolls, which can increase drivers' willingness to pay the monetary toll costs. In practice, however, the evidence is not consistent with this alternative explanation for the increase in toll rates under ETC. In particular, two distinct experiments in the data show no detectable increase in toll rates associated with reductions in compliance costs. First, I find no evidence that ETC is associated with larger toll increases on roads where, prior to ETC, compliance costs were a larger share of the total toll (i.e. compliance cost + monetary toll). Second, I find no detectable increase in toll rates when bridges and tunnels switch from charging tolls in both directions to charging tolls in only one direction, which produces a comparable reduction in compliance costs to that expected under steady state ETC penetration.

I also present evidence that other aspects of ETC are unlikely to be able to explain my findings. For example, the rise in tolls associated with ETC is difficult to explain by the reduction in operating costs associated with toll collection, or by the capital outlay required to install ETC. The evidence also suggests that the timing of ETC adoption is not spuriously correlated with increased toll rates.

The analysis in this paper is perhaps most similar in spirit to Becker and Mulligan (2003). They formalize the closely related theoretical idea that a more efficient tax system can raise the equilibrium size of government. Consistent with this theory, they present cross-country evidence that countries with more efficient tax systems have larger government sectors, and within-country evidence that exogenous increases in government spending needs decrease discretionary spending while exogenous increases in government revenue increase government spending. ${ }^{1}$

\footnotetext{
${ }^{1}$ As another empirical test of the relation between tax efficiency and the size of government, Dusek (2003) examines the introduction of state income tax withholding. He finds that withholding is associated with a mechanical increase in revenue due to less tax evasion, but not with any change in statutory income tax rates. However, his analysis also suggests that the decision to adopt state income tax withholding may be correlated with increased demand for bigger government, making the results hard to interpret. In Section 5.2 below I discuss several pieces of evidence that suggest that the adoption of ETC is not correlated with increased demand for revenue.
} 
The rest of the paper proceeds as follows. Section 2 provides a conceptual framework for the likely effects of a decline in tax salience. Section 3 describes the data. Section 4 presents the main empirical results. Section 5 considers a range of alternative explanations for the empirical findings. The last section concludes.

\section{Effects of Tax Salience: Conceptual framework.}

In a fully salient tax system, individuals are aware of actual tax rates as they make economic decisions. In a less salient tax system, some individuals do not directly observe the actual tax when making economic decisions. Instead, they form a belief about the tax, which I refer to as the perceived tax. A natural way to model a decrease in the salience of the tax system is as an increase in the fraction of consumers who do not directly observe the actual tax when making economic decisions. Thus, for example, an increase in the proportion of tolls paid electronically might correspond to a decrease in the salience of the tax system. In this section, I discuss why the theoretical effect of a decline in tax salience on the equilibrium tax rate is ambiguous.

Consider first a model in which individuals have rational expectations but government lacks the ability to commit on policy. In a less than fully salient tax system, some portion of individuals will not directly observe the tax, and will instead form an (unbiased) expectation about its level. Conditional on this expectation, any change in the tax will act as a non-distortionary, lump-sum tax on these individuals. Under many standard assumptions about the government's objective in setting taxes - including a profit maximizing (Leviathan) government, a government solving the Ramsey (1927) optimal commodity tax problem, and a government solving the Mirrlees (1971) optimal income tax problem - the government will therefore have an incentive to raise the tax above the full salience equilibrium tax rate. Rational consumers will, of course, take this government reaction into account in forming expectations. The equilibrium tax rate will therefore be higher under a less salient system, but so will the equilibrium distortions from the expected tax, since consumers have accurate expectations about the tax rate. This is just a specific example of the well-known result that a lack of commitment power by the government can result in sub-optimal policy (e.g. Kydland and Prescott, 1977, Barro and Gordon 1983). This result 
depends critically of course, on the inability of the government to commit on policy; in the same setting but with commitment, the decline in salience would not affect the equilibrium tax rate.

The preceding discussion assumes rational expectations. However, in keeping with the public choice tradition of "fiscal illusion", people may have systematically biased perceptions about taxes. Recent empirical evidence is consistent with this view. For example, Liebman and Zeckhauser (2004) and Feldman and Katuscak (2005) show that individual responses to the non-linear income tax schedule are consistent with confusion about marginal tax rates, an idea that Liebman and Zeckhauser (2004) term "schmeduling." A decline in the salience of the tax system may increase the extent of tax misperception. Consistent with this hypothesis, Chetty et al. (2006) find that when the sales tax is included in the posted price - and presumably therefore more salient - consumer purchases are more likely to respond to the after-tax price than to the pre-tax price.

If the government lacks commitment power, what matters for the effect of tax salience on tax rates is how tax salience affects perceptions - or misperceptions - of tax changes. If, as in the previous discussion with rational expectations, a decline in tax salience reduces the proportion of individuals who directly observe tax changes, then it will be associated with an increase in tax rates, since individuals will be less responsive to any given tax increase. Whether or not individuals' expectations of tax levels are unbiased, or systematically over- or under-estimates will be important for the long-run distortionary effect of the tax, but not for government behavior.

However, it may be that individuals always observe whether a tax change occurs, but that a decline in tax salience reduces the proportion of individuals who directly observe the magnitude of the tax change. Then a decline in tax salience may have an ambiguous effect on the tax rate, depending on whether it causes more individuals to over-estimate the magnitude of the tax change, or to under-estimate it. Suppose the government uses the revenue from the taxed good to finance a public good (and continues to lack commitment power). The efficiency cost of raising taxes to increase the level of the public good is 
likely increasing in the perceived tax increase. ${ }^{2}$ The government will therefore have an incentive to raise taxes (relative to the full salience case) if individuals under-estimate tax changes, and lower taxes if individuals over-estimate tax changes; with rational expectations about the tax change, the government will not change taxes.

The preceding discussion highlights another empirical prediction which I will investigate below: at least in the simple models described above, if a decline in tax salience is associated with an increase in tax rates, it should also be associated with a decline (in absolute value) in the short run elasticity of demand with respect to the actual tax. For a government lacking commitment power has an incentive to raise taxes if a decline in salience causes individuals to under-estimate (or in the extreme, to not observe at all) tax changes. Conversely, if individuals over-estimate the tax change, the short run elasticity of demand would increase (in absolute value), and taxes would be expected to fall. Note that this is a prediction about the short run elasticity of demand with respect to the actual tax change; the elasticity of demand with respect to the expected tax will remain unchanged in a rational expectations model, and will increase or decrease (in absolute value) if individuals over- or under-estimate the tax level, respectively. ${ }^{3}$

Finally, it is worth noting that the normative implications of an increase in tax rates associated with a decline in tax salience are ambiguous. In the rational expectations model with time inconsistency, the higher tax rate under a less salient system is sub-optimal. However, a government that maximizes social welfare might choose to adopt a less than fully salient tax system if the negative consequences of the

\footnotetext{
${ }^{2}$ This statement requires some additional assumptions, which further highlights the ambiguous sign of an effect of decreased tax salience on tax rates. A specific set of assumptions that would rationalize the statement would be if individuals choose the level of consumption of two goods, a taxed good and an untaxed good, and we assume that the individual first makes a consumption decision about the taxed good, based on the perceived tax, and then allocates his actual remaining income to the untaxed good. Misperception of a change in the tax rate has two effects: a price effect which affects relative demand for the taxed good, and an income effect via the budget constraint. If we also assume utility is quasi-linear in the untaxed good and that there is an interior solution, the effects of misperception via the budget constraint are fully born by the untaxed good. These assumptions are likely to be reasonable when the taxed good is small relative to the total budget, as in the case of tolls. In more general settings, the change in the tax rate associated with decreased salience will also depend on how the individual satisfies the true budget constraint in a world with misperception, which in this simple example we have assumed is fully born by the untaxed good, as well as the other tax instruments at the government's disposal (e.g. tax rates on other goods).

${ }^{3}$ Note too that the change in the short run elasticity is the partial equilibrium effect of a decline in tax salience. Since the government will respond to the change in elasticity by changing taxes, the effect of tax salience on the equilibrium elasticity is not obvious. I discuss this issue in the context of the empirical work in Section 4.2 below.
} 
decline in salience are outweighed by the improved efficiency of tax collection that often occur in less salient tax systems (such as federal income tax withholding or electronic toll collection). Moreover, if individuals systematically under-estimate tax levels in a less salient tax system, this may reduce the efficiency costs of taxation and therefore the increase in taxes may be socially optimal in its own right, regardless of other efficiency gains from the less salient tax system. Finally, the choice of a less salient tax system may reflect government failure - as in, for example, the political competition models of Wilson (1990) and Becker and Mulligan (2003) - and the choice of a less salient tax system may well reduce social welfare. ${ }^{4}$

\section{Data and Descriptive Statistics}

\subsection{Sample construction}

My target sample is all publicly-owned toll facilities in the United States (excluding ferries) that were charging tolls in 1985. I chose the year 1985 to ensure at least 20 years of toll rate history on each facility, as well as data on all roads prior to the first facility's adoption of ETC in the United States (which occurred in 1987). As a result, my analysis is limited to the impact of tax salience on the level of existing taxes, and will not pick up any effect that decreased salience has on the decision to introduce a new tax on a previously untaxed good.

At the start of my sample period in 1985, tolls on roads, bridges, or tunnels raised about $\$ 2.5$ billion dollars in revenue for state and local governments, or about 0.8 percent of total state and local tax revenue in the 31 states that levied such tolls (US Department of Transportation 1985 and 1986, and U.S. Census Bureau 1985.) Toll revenues are therefore on a par with lottery profits in terms of contribution to public coffers (Kearney, 2005). Operating authorities generally have the statutory authority to change tolls (at least within certain bounds). In practice, however, they are likely limited in how free they are to operate independently of the state government and its political concerns.

\footnotetext{
${ }^{4}$ In a similar vein, Acemoglu and Robinson (2002) show that groups may prefer inefficient forms of redistribution toward them as more inefficient form of redistribution increases their group size and hence their ability to secure future redistribution.
} 
In general, local laws require that toll revenues be spent on the toll facility itself (e.g. maintenance and operating expenses, or expansion). The increases in toll rates and toll revenues which I estimate are associated with ETC are likely used for some combination of financing improvements or expansions in the facility, and/or in increasing employment (or salaries) at the toll authority; unfortunately, the available data do not exist to allow a careful examination of the uses of the increased revenue. However, as I discuss in Section 5.2, it does not appear that the increase in toll revenue associated with ETC is offset by reductions in other highway taxes such as motor vehicle user fees or gasoline taxes.

To construct the necessary data, I contacted each toll operating authority and requested toll rate histories for each of their toll facilities from 1950 or its opening (whichever was later) through 2005. I also requested the date (if any) that ETC was adopted, annual traffic and revenue data, and the annual fraction of traffic and revenue accounted for by ETC. The data collection effort took place mainly in the first six months of 2006. I consider the data usable if it contains the date of ETC adoption and toll rate histories back to at least 1985 .

The target sample consisted of 183 toll facilities run by 88 operating authorities in 31 states. $^{5}$ I was able to collect usable data for 123 facilities run by 49 different operating authorities in 22 different states. I assigned each facility to one of 24 different state-like entities to reflect the fact that certain operating authorities - specifically, the Port Authority of New York and New Jersey, the Delaware River Joint Toll Bridge Commission, and the Delaware River Port Authority - are under the purview of two states, which I code as a separate state (either "NYNJ" or "NJPA" as relevant). Appendix A provides more detail on characteristics of the target facilities and the acquired facilities, as well as the data for the acquired facilities. For the remainder of the paper, all statistics refer to the acquired facilities.

On average, the data contain 50 years of toll data per facility. About sixty percent of the facilities are bridges or tunnels; the remainder consists of roads (and a few causeways which I classify as roads).

\subsection{Key variables}

\footnotetext{
${ }^{5}$ I use the term toll "facility" to denote a particular road, bridge, tunnel or causeway; a complete list of facilities is given in the Appendix.
} 
This section gives a brief overview of the definitions and summary statistics for the key variables. Appendix A provides more detail.

\subsubsection{ETC Adoption and Diffusion}

With ETC, the toll amount is automatically deducted from a pre-paid toll account as the car drives through a toll plaza. When the balance in the driver's account follows below some replenishment threshold (often \$10), the replenishment amount is automatically charged to the driver's credit card, or debited from his bank account. The driver's credit card or bank statement will indicate that a charge has occurred, but does not provide itemized expenses.

About 70 percent of the facilities ( 87 out of 123) adopted ETC by 2005. Figure 1 shows a histogram of adoption dates. They range from 1987 through 2005. The median adoption date is 1999 . Almost all the variation in whether ETC is adopted - and in adoption dates conditional on adopting - is between rather than within operating authorities; this is not surprising, given that the operating authority is the primary decision maker regarding tolls. By contrast, there is substantial variation across operating authorities within a state in whether ETC is adopted and in the adoption date, conditional on adopting ETC. Appendix A provides more detail.

Table 1 shows that relationship between facility characteristics and ETC adoption. ETC adoption rates are highest in the Northeast (70 percent) and lowest in the West (30 percent). The high adoption rates in the Northeast may reflect higher labor costs (since ETC reduces labor costs of toll collection) as well as greater urbanicity (since ETC may help reduce congestion). ETC adoption rates are higher and adoption dates are earlier on roads than on bridges and tunnels. There does not appear to be any relationship between the age of the facility and whether ETC is adopted; however, conditional on adoption, older facilities tend to adopt earlier (not shown).

Once a facility adopts ETC, use of the technology diffuses gradually across drivers. To characterize the extent of ETC diffusion on a facility, I define the ETC penetration rate as the fraction of toll transactions or the fraction of toll revenue collected by ETC. The definition varies across (but not within) facilities depending on which measure I could obtain for more years; all of the analysis will look at 
within-facility changes. I was able to collect data on ETC penetration rates for about two-thirds of the facility-years in which ETC is in place. Figure 2 shows the within-facility diffusion rate of ETC. It takes about 14 years for ETC to reach its steady state penetration rate of 60 percent. $^{6}$

\subsubsection{Toll histories}

I define the toll as the nominal toll rate for passenger cars. High frequency (i.e. commuter) discounts are not coded. None of the facilities offer time-of-day varying prices. I collected data on both the "manual" (i.e. cash) toll rate and any discount offered for the electronic toll.

Over half (53 out of 88) of facilities that have ETC offered discounted tolls to ETC users at least at some point in time; the electronic toll is never more than the cash toll. ETC discounts are presumably designed to encourage use of the technology; consistent with this, they are more common on facilities that adopted ETC earlier. The discounts may also be rationalized as a Pigouvian subsidy if ETC has positive externalities on congestion reduction. The average ETC discount - when offered - is about 15 percent off of the manual toll. I use the short-hand "minimum toll" to refer to the lower envelope of the manual and electronic toll. The change in the log minimum toll will be the primary toll measure used in the analysis of the impact of ETC on toll rates. I also present results for the sample of facilities that never offer ETC discounts, and for which the minimum and manual toll are therefore always the same.

I define the toll rate on a road as the cost of a full length trip on the road, and I define the toll rate on bridges, tunnels, or causeways as the round-trip cost on that facility. In 2005, the average (manual) toll was $\$ 5.41$ for a full length trip on a road (implying an average per-mile toll of $\$ 0.063)^{7}$ and $\$ 3.03$ for a round-trip on a bridge or tunnel.

On average, the minimum toll increased by 2.0 percent per year over my sample. This is substantially below the weighted average annual rate of inflation of 4.2 percent in facility-years between 1950 and 2005 in my sample (based on the CPI-U). Toll changes are lumpy; in a given year, on average only 7.7

\footnotetext{
${ }^{6}$ Note that the percentage of tolls or revenue collected by ETC is likely an over-estimate of the percentage of drivers who use ETC, as drivers who adopt ETC tend to drive more than those who do not adopt ETC (Amromin et al., 2005).

${ }^{7}$ Mileage data for a full length trip were taken from U.S. Department of Transportation (2003) or information from the operating authority's web site.
} 
percent of facilities increase their minimum toll and only 1 percent of facilities decrease it. These statistics are all very similar for manual tolls.

Although by construction all facilities are charging a toll at the start of the sample, 15 of the 123 facilities reduce the toll to zero later in the sample. Since the main dependent variable in the analysis of the effect of ETC on toll rates is $\Delta \log (\text { minimum toll })_{\text {it }}$, the occurrence of zero toll rates raises a potential concern about selection on the dependent variable. However, I show below that this selection biases against finding an effect of ETC on toll increases; not surprisingly, tolls are less likely to be set to zero after ETC has been introduced.

\subsubsection{Revenue and traffic data}

I considered data on toll revenue or toll traffic usable if I was able to get at least 10 years of facilitylevel data. I was able to collect usable traffic data for about 60 percent (76 out of 123) of facilities, and usable revenue data for over one third (45 out of 123) of facilities. For a facility with usable data, on average I collected 34 years of data. Over the sample, traffic on a facility grew on average by 4.9 percent per year and (nominal) facility revenue by 7.7 percent.

\section{The impact of ETC}

\subsection{The Impact of ETC on toll rates}

\subsubsection{Main results}

A basic estimating equation to examine the effect of ETC on toll rates would be:

$$
\log (\text { minimum toll })_{i t}=\gamma_{t}+\alpha_{i}+\beta_{1} E T C_{i t}+\beta_{2} E T C_{-} Y e a r_{i t}+\varepsilon_{i t}
$$

The dependent variable is the log of the minimum toll, where the minimum toll is defined as the lower envelope of the manual and electronic toll. The $\gamma_{t}$ 's represent a full set of year dummies which control for any common secular changes in toll rates across facilities. The $\alpha_{i}$ 's represent a full set of facility fixed effects that control for any fixed differences across facilities in the toll rate. I specify the dependent variable in logs rather than levels because a specification in levels would constrain toll rates in different 
facilities to grow by the same absolute amount each year. This would be inappropriate, given the considerable variation in toll rates across facilities.

The key coefficients of interest are those on $E T C_{i t}$ and ETC_ Year $_{i t}$. The variable $E T C_{i t}$ is a dummy variable for whether facility $i$ has ETC in year $t$. The coefficient on $E T C_{i t}$ measures any level shift in tolls associated with having ETC on a facility. Since ETC use among drivers diffuses gradually across a facility, it is likely that any impact of ETC on toll rates will be phased in gradually. To capture this, I include the variable ETC_Year ${ }_{i t}$ which measures the number of years the facility has had ETC; it is zero in the years prior to ETC adoption, 1 in the year the facility adopts ETC, 2 in the next year and so forth. The coefficient on ETC_Year ${ }_{i t}$ measures how the toll rate changes over time after the facility adopts ETC. Finally, $\varepsilon_{i t}$ is a random disturbance term capturing all omitted influences.

A practical problem with estimating equation (1) is that toll rates are highly auto-correlated. A regression of the residuals from estimating equation (1) on their lag produces a coefficient of 0.92 . This suggests estimating the first-differenced version of equation (1) (Wooldridge 2002, p.274 - 281): $\Delta \log (\min \text { toll })_{\mathrm{it}}=\gamma_{t}+\beta_{1} \Delta E T C_{i t}++\beta_{2} \Delta E T C_{-}$Year $_{i t}+\Delta \varepsilon_{i t}$

The resultant residuals are much less serially correlated; a regression of the residuals from equation (2) on their lag produces a coefficient of -0.045 . Note that in the first-differenced equation, $\triangle E T C_{i t}$ is an indicator variable for whether facility $i$ adopted ETC in year $t$, and $\triangle E T C Y_{-}$ear $r_{i t}$ is an indicator variable for whether the facility has ETC. The coefficient on $\triangle E T C Y e a r_{i t}$ thus measures the average annual growth in facilities' tolls once they have ETC. On average for a facility with ETC, I observe about 6 years of ETC on that facility.

I estimate equation (2) allowing for an arbitrary variance-covariance matrix within each of the 24 "states"; this error structure allows for both auto-correlation in toll changes within a facility and contemporaneous correlation in toll changes among facilities in the same state; the standard errors are quite similar if I instead cluster on the operating authority or facility. I give equal weight in the regression 
to each of the 49 operating authorities, so as to give equal weight to each toll-setting (and ETC adopting) decision body; in practice, I show below that the results are not sensitive to alternative weighting schemes.

The first column of Table 2 shows the results from estimating equation (2). The coefficient on $\triangle E T C$ Year $_{i t}$ is $0.015($ s.e. $=0.006)$. This indicates that once a facility has ETC, its toll increases each year by 1.5 percent more than it otherwise would have. This effect is both statistically significant and economically large. Relative to the average annual 2 percent increase in tolls, it implies that after installing ETC, the facility's toll rate rises by 75 percent more per year than it did prior to ETC.

The toll change in the first year of ETC is given by the sum of the coefficients on $\triangle E T C_{i t}$ and $\triangle E T C Y e a r_{i t}$ in column 1 . Interestingly, these coefficients suggest that there is a (statistically insignificant $)$ decline in tolls the year that ETC is adopted of 3.6 percent $(=0.015-0.051)$. The results in the next two columns suggest that any decline in the toll the year that ETC is adopted reflects the effect of ETC discounts. In column 2, I re-estimate equation (2) but with the change in the log manual toll (rather than the change in the log minimum toll) as the dependent variable. In column 3 I re-estimate equation (2) for the 60 percent facilities that never offered an ETC discount and for whom therefore the manual and minimum toll are always the same; this sub-sample includes facilities that never adopted ETC (approximately 30 percent) and facilities that adopted ETC but never offered a discount (approximately 30 percent). In these alternative specifications, the sum of the coefficients on $\triangle E T C_{i t}$ and $\triangle E T C$ Year $_{i t}$ now indicate either a statistically insignificant 3.6 percent increase in the toll in the year ETC is adopted (column 2), or an economically and statistically insignificant decline of -0.9 percent (column 3). Moreover, both of the alternative specifications indicate a growth in tolls once a facility has ETC; the coefficient on $\triangle E T C Y_{e a r}$ is statistically significant and, indeed, slightly larger than in the 
baseline specification in column $1 .{ }^{8}$ The results from the "no discount" sample (column 3 ) indicate that the estimated growth in tolls after ETC is installed does not merely reflect a recouping of first-year losses caused by the ETC discount.

The preceding analysis constrains the effect of ETC on tolls to be the same across facilities and to be constant over time after the adoption of ETC. However, if the mechanism for ETC's effect on tolls is through reduced salience, we would expect the effect to be increasing in the ETC penetration rate. The growth in ETC penetration is not constant over time (see Figure 2) or across facilities (not shown). As a stronger test of the salience hypothesis, I therefore re-estimate equation (2) using the percentage point change in the ETC penetration rate $\left(\triangle E T C{ }_{-}\right.$Penetration $\left._{i t}\right)$ instead of the change in ETC year on the right hand side. However, I can only estimate this alternative specification for the 60 percent of facilities that never offer an ETC discount; for facilities that offer an ETC discount, changes in the discount will affect both the diffusion of ETC $\left(\triangle E T C{ }_{-}\right.$Penetration $\left._{i t}\right)$ as well as the dependent variable $\Delta \log (\text { minimum toll })_{\mathrm{it}}$, raising the potential for biased estimates. Column 4 shows the results. The coefficient on $\triangle E T C{ }_{-}$Penetration $_{i t}$ is 0.623 (s.e. $=0.285$ ). The coefficient indicates that every 10 percentage point increase in ETC penetration is associated with a (statistically significant) increase in the toll of about 6.2 percent.

For the full sample of facilities, I can estimate an instrumental variables version of equation (2) in which I instrument for $\triangle E T C C_{-}$Penetration $_{i t}$ with $\triangle E T C Y e a r_{i t}$. Column 5 shows these results. The coefficient on $\triangle E T C_{-}$Penetration $_{i t}$ is 0.557 (s.e. $=0.262$ ), indicating that every 10 percentage point increase in ETC penetration is associated with a (statistically significant) 5.6 percent increase in the toll. To allow the increase in toll rates associated with ETC to vary over time after the year of ETC adoption, in column 6 I instead instrument for the change in ETC penetration with a cubic polynomial in ETC year.

\footnotetext{
${ }^{8}$ Although it might at first appear puzzling in column 2 that the cash toll - which has become no less salient - also increases once ETC is installed, this is easily understood by the necessary linkage between cash and electronic toll rates; were the electronic rate to increase while the cash rate did not, this would presumably discourage use of ETC.
} 
The coefficient on $\triangle E T C \_$Penetration $_{i t}$ is now 0.501 (standard error $=0.261$ ). This is quite similar to the results from the constant annual effects specification in column 5. Results using a series of grouped dummies for the number of years under ETC to instrument for $\triangle E T C{ }_{-}$Penetration $_{i t}$ also produce similar results (not shown). Relatedly, if I replace the single indicator variable for whether a facility has ETC $\left(\triangle E T C Y e a r_{i t}\right)$ with a series of grouped dummies for various numbers of years the facility has had ETC (e.g 1- 6, 7-11, or 12+), I find that ETC is associated with increased toll rates of similar magnitude in each of these sub-periods (not shown); this suggests that the effect of ETC persists over the time period under ETC that I can observe in my data.

The magnitude of the toll increase associated with ETC is similar across the various specifications shown in Table 4. In the full sample, the results from the baseline specification (column 1) suggest that after 14 years, by which point ETC has diffused to its steady state level (see Figure 2), ETC is associated with an increase in the toll rate of 17 percent, or about one-fifth $\left(\sim \exp \left(\beta_{\Delta \mathrm{ETC}}+14 * \beta_{\Delta \mathrm{ETCYear}}\right)\right)$. The IV estimates in columns 5 and 6 are similar, suggesting that once ETC has diffused to its steady state level of $60 \%$, ETC is associated with an increase in tolls of 26 and 23 percent respectively $\left(\sim \exp \left(\beta_{\triangle \mathrm{ETC}}+\right.\right.$ $\left.0.6^{*} \beta_{\triangle \mathrm{ETC} \_ \text {Penetration }}\right)$ ). When the sample is limited to facilities without ETC discounts, the implied steady state increase in tolls is 36 percent in the baseline specification (column 3), and 38 percent when $\triangle E T C$ Penetration ${ }_{i t}$ is included on the right hand side (column 4). All of these implied steady state toll increases associated with ETC are statistically significant at at least the 10 percent level. Taken together, these estimates suggest that the diffusion of ETC to its steady state level is associated with a 20 to 40 percent increase in toll rates.

Finally, to explore the mechanics behind the increase in tolls associated with ETC, I re-estimate equation (2) with a binary dependent variable for whether the minimum toll increased over the last year. Column 7 shows the results. Given the baseline probability of a toll increase of 7.7, the coefficient of $0.073($ s.e. $=0.024)$ on $\triangle E T C$ Year $_{i t}$ suggests that the probability of a toll increase almost doubles on a facility once it has ETC. Together with the results in the preceding columns, this suggests that the 
increase in tolls associated with ETC comes about through more frequent toll increases, but not changes in the magnitude of a toll increase when it occurs.

\subsubsection{Alternative specifications}

The identifying assumption behind all of the estimates in Table 2 is that absent the introduction of ETC on facility $i$ in year $t$, toll rates would not have changed differentially for that facility. The fact that, as discussed in Section 3, observable characteristics of the facility are correlated with whether and when a facility adopts ETC raises concern about the validity of this assumption. Table 3 therefore investigates a variety of alternative specifications that shed some light on this issue. The first column replicates the baseline specification (column 1 from Table 2). The next 6 columns stratify the sample on various observable characteristics that are correlated with whether and when a facility adopts ETC. Columns 2 and 3 examine the effect of ETC separately by region (Northeast and Midwest vs. South and West), columns 4 and 5 examine the effect separately by facility type (roads vs. bridges and tunnels), and columns 6 and 7 examine the effect separately for facilities of different ages (opened after $1960 \mathrm{vs.}$ opened 1960 or before). Not only does statistical significance tend to persist in the (sometimes much smaller) sub-samples, but the point estimates remain remarkably similar across the different samples. This helps alleviate concerns that the estimated effect of ETC is spuriously picking up differences across facilities in their underlying rate of toll growth that are correlated with ETC adoption. To more directly control for this possibility of spurious findings, column 8 shows that the results in the baseline specification are robust in both magnitude and statistical significance to the addition of facility fixed effects, which (given the first-differences specification) control for any facility-specific linear trend in toll rates. As perhaps the most direct partial test of the identifying assumption, in section 5.2 below I show that there is no substantive of statistically significant change in the pattern of changes of toll rates, traffic or revenue in the years prior to a facility's adoption of ETC.

The last four columns of Table 3 show the robustness of the baseline finding along several other dimensions. Column 9 shows that the results are unaffected by restricting the analysis to years 1985 and later. The results are not sensitive to weighting each state equally (column 10) or weighting each facility 
equally (column 11), rather than weighting each operating authority equally as in the baseline specification. ${ }^{9}$ Finally, the last column shows that the estimated impact of ETC also appears in the subsample of facility-years for which I have traffic data, which I will analyze in the next sub-section; although the coefficient on $\triangle E T C Y e a r_{i t}$ is only significant at the 15 percent level in this more limited sample, the point estimate of $0.012($ s.e. $=0.008)$ is quite similar to the baseline estimate in column 1 of 0.015 (s.e. $=0.006)$.

To address potential concerns that might arise from the censoring of observations with a zero toll rate in the current or previous year, I re-estimate equation (2) by OLS using as the dependent variable an indicator variable for whether the toll rate on facility $i$ in year $t$ became zero from a non-zero rate. This occurs in 0.3 percent of the sample. I estimate a negative, and marginally statistically significant coefficient on both $\triangle E T C_{i t}$ and $\triangle E T C Y e a r_{i t}$ (not shown). This suggests that, not surprisingly, facilities may be less likely to set tolls to zero when they have ETC; indeed, only 1 of the 15 facilities that set the toll to zero after 1985 adopted ETC (compared to 86 of the 108 facilities that never set their toll to zero after 1985). This suggests that, if anything, the censoring of zero toll observations biases downward the estimated effect of ETC on toll rates. I am reluctant, however, to include the lower likelihood of setting toll rates to zero as part of the estimated effect of ETC, as operating authorities that are planning to set a toll to zero in a few years may be less inclined to introduce ETC on the facility.

Finally, one might be concerned that increases in the minimum toll in the years after ETC is adopted may reflect increases in the electronic toll as it is raised to be closer to the manual toll, rather than a shift in the entire toll schedule. Such a concern does not arise when the sample is limited to facilities that do not offer ETC discounts (columns 3 and 4 of Table 2). Moreover, for facilities that do offer ETC discounts, there does not appear to be any systematic change in the magnitude of the discount with respect

\footnotetext{
${ }^{9}$ Another natural alternative might be to weight each facility by its size (i.e. traffic or revenue). Unfortunately, I was only able to collect traffic data at the same point in time for at most 92 of the 123 facilities. For these three-quarters of facilities, it does not appear that the effect of ETC varies with facility size. The coefficient on $\triangle \mathrm{ETCYear}$ is 0.017 (s.e. $=0.011)$ in an unweighted regression and $0.018(\mathrm{~s} . \mathrm{e} .=0.013)$ when each facility is weighted by the average number of toll transactions in 2003 - 2005 (not shown).
} 
to the number of years the facility has had ETC (not shown). This suggests that in practice increases in the minimum toll reflect a shift of the entire toll schedule; this is consistent with the finding that the manual toll also increases after ETC is introduced (column 2 of Table 2). The preservation of ETC discounts may reflect continued attempts to induce more drivers to switch to ETC; the maximum ETC penetration rate in my sample is only 78 percent. It may also arise if drivers using ETC are aware of the existence of the electronic discount, even if they are not full aware of toll changes.

\subsection{The Impact of ETC on the elasticity of driving with respect to a toll change}

The preceding results suggest that the diffusion of ETC is associated with higher toll rates. As discussed in Section 2, if this effect is due to the lower salience of tolls under ETC, it is likely that ETC will also be associated with a decline (in absolute value) in the short run elasticity of demand with respect to the actual toll. In this section, therefore, I investigate how the short run elasticity of demand with respect to a toll change changes as ETC diffuses within a facility. An important caveat to the analysis is that, as the previous section demonstrated, tolls are also higher under ETC, and the higher toll rates may have a direct effect on the elasticity. Nonetheless, the results may be viewed as suggestive.

I estimate:

$$
\begin{aligned}
\Delta \log \left(\text { traffic }_{i t}=\gamma_{t}\right. & +\beta_{1} \Delta \log \left(\text { minimum toll }_{i t}\right)+\beta_{2} \Delta \log \left(\text { minimum toll }_{i t}\right) * \text { Never_ETC }_{i} \\
& +\beta_{3} \Delta \log \left(\text { minimum toll }_{i t}\right) * \text { ETC_year }_{i t} \\
& +\beta_{4} \text { Never_ETC }_{i}+\beta_{5} \text { ETC_year }_{i t}+\mu_{i t}
\end{aligned}
$$

Equation (3) examines the relationship between the annual percent change in a facility's traffic $\left(\Delta \log (\text { traffic })_{i t}\right)$ and its annual percent change in its toll $\left(\Delta \log (\text { minimum toll })_{i t}\right)$. It allows this relationship to vary across facilities based on whether the facility ever adopted ETC $\left(\right.$ Never_ETC $_{\mathrm{i}}$ is 1 if the facility never adopts ETC and zero other wise), and by the number of years the facility has had ETC (ETC_Year), which is a reduced form proxy for the ETC penetration rate on the facility. Once again, $\gamma_{t}$ represents a full set of year fixed effects; these control for any secular changes in traffic over time. The key coefficient of interest in $\beta_{3}$; this indicates how the elasticity changes on a facility under ETC. Once again, I allow for an arbitrary variance-covariance matrix within each of the 24 "states" and give equal weight in the 
regression to each of the 50 operating authorities. Note that equation (3) estimates the short-run (i.e. within a year) elasticity of demand with respect to actual toll changes which, as discussed in Section 2, is likely to fall (in absolute value) under a less salient tax system.

Estimation of equation (3) is based on the assumption that changes in tolls are not affected by contemporary changes in demand. This is probably a reasonable assumption. Traffic - and presumably underlying demand for driving - changes continuously each year, while a facility's toll is only raised on average every 8 to 9 years. The infrequency of toll adjustment likely reflects both general lags in price setting by government enterprises as well as political constraints; for example, I find that tolls are less likely to be raised in the year the governor is up for re-election (not shown). Although tolls may be adjusted in part based on past demand shocks (i.e. lagged values of changes in traffic), changes in traffic within a facility show very little serial correlation; a regression of the residuals from equation (3) on their lag produces a coefficient of only 0.045 . Any adjustment of tolls to past changes in demand may therefore not pose much of a practical problem for estimation of equation (3). However, in light of the potential concern that past changes in traffic may be correlated with both current changes in tolls and current changes in traffic, I also report results from estimation of equation (3) in which I limit the sample to the years in which a toll changes or the 2 years before or after a toll change; I refer to this as the " $+2 /-2$ sample". The assumption in this more limited sample is that the timing of the toll change is random with respect to short-run traffic changes, although it may reflect longer run demand changes.

As discussed in Section 2, the prediction that the short run elasticity of demand will decline (in absolute value) with a decline in tax salience is a partial equilibrium prediction; the government is expected to respond to this decline in elasticity by raising taxes, so that, in equilibrium, the elasticity need not decline. However, as long as the toll authorities do not immediately and fully adjust the toll in response to the change in elasticity associated with ETC - an assumption implied by the econometric assumptions needed for equation (3) to be identified that I discussed in the previous paragraph -we expect to find a decline (in absolute) value in the elasticity associated with ETC. 
Table 4 reports the results of estimating variants of equation (3). Column 1 shows the results when the only regressor (besides the year fixed effects) is $\Delta \log (\text { minimum toll })_{\mathrm{it}}$. The coefficient on $\Delta \log (\text { minimum toll })_{\mathrm{it}}$ of $-0.049($ s.e. $=0.015)$ indicates that a 10 percent increase in tolls is associated with a statistically significant but economically small $0.5 \%$ reduction in traffic. This suggests that tolls are set below the profit maximizing rate. This is consistent with Peltzman's (1971) observation that there will be a downward bias in the prices set by government-owned enterprises.

Column 2 estimates the complete equation specified by equation (3). The coefficient on $\Delta \log \left(\right.$ minimum toll $\left._{i t}\right) *$ ETC_Year $_{\text {it }}$ is $0.002($ s.e. $=0.002)$. The positive coefficient suggests that drivers' elasticity declines (in absolute value) per year the facility had ETC; however the estimate is not statistically significant at conventional levels $(\mathrm{p}=0.21)$.

However, ETC discounts introduce measurement error in the minimum toll (or equivalently, the manual toll) once a facility has ETC, as the average toll rate depends on the fraction of tolls paid electronically. Measurement error in the toll rate that occurs once ETC is adopted may bias the estimated change in the elasticity associated with an additional year of ETC toward zero. In column 3 I therefore repeat the analysis in column 2 , limiting the sample to the $60 \%$ of facilities that never offer an ETC discount. In this sample, there is only one toll rate, and therefore introduction of ETC does not introduce measurement error in the toll rate regressor. The results are consistent with the hypothesis that measurement error biases the estimated change in elasticity associated with an additional year of ETC toward zero in the full sample in column 2. In column 3, the coefficient on the key interaction term $\Delta \log \left(\right.$ minimum toll $\left._{i t}\right) *$ ETC_Y $_{-}$ear $_{\text {it }}$ increases to $0.006($ s.e. $=0.001)$, and is now statistically significant at the 1 percent level. This suggests that the elasticity of driving with respect to the toll declines (in absolute value) by 0.006 per year that the facility has ETC, or by about 10 percent relative to the average estimated elasticity prior to ETC of -0.057 . Reassuringly, the coefficient on $\Delta \log (\operatorname{minimum}$ toll) $)_{\text {it }}$ changes only slightly with the restriction of the sample to facilities that never offer ETC discounts (compare columns 3 and 2). Since this coefficient measures the elasticity when a facility does not have 
ETC, it is not subject to the same measurement error concerns in column 2 and therefore would not be expected to change. The negative coefficient on $\Delta \log (\text { minimum toll })_{i t} *(\text { Never_ETC })_{i}$ suggests that driving may be more elastic on facilities that never adopt ETC; however this effect is never close to statistically significant in any specification.

As previously discussed, in the sub-sample of facilities that never offer ETC discounts I can include the ETC_Penetration rate directly on the right hand side in place of its proxy ETC_Year. Column 4 shows the results. The coefficient on $\Delta \log \left(\right.$ minimum $\left._{\text {toll }}{ }_{i t}\right) *$ ETC_penetration $_{\text {it }}$ is $0.134($ s.e. $=0.038)$; this indicates that a 5 percentage point increase in the ETC penetration rate (which is the average increase per year of ETC) is associated with a (statistically significant) 0.0067 decline in the elasticity of driving with respect to the toll; this is quite similar to the estimated decline of 0.006 per year of ETC in column 3 .

The last two columns repeat the analysis in columns 3 and 4 on the $+2 /-2$ sample. The point estimates on both the elasticity of driving under manual toll collection and the change in the elasticity associated with ETC_Year (or ETC_Penetration) remain virtually unchanged. Moreover, the change in the elasticity associated with ETC_Year (or ETC_Penetration) remains statistically significant, although at the 10 percent level in the $+2 /-2$ sample (columns 5 and 6 ) rather than at the 1 percent level as in the larger samples (columns 3 and 4).

\subsection{Cross checking the estimated magnitudes}

An interesting exercise is to compare the estimated change in the toll rate associated with ETC to the change in price that we would expect based on the estimated change in elasticity under ETC. This section does such a back-of-the-envelope calculation and shows that, in fact, the predicted and actual changes in the toll rate are quite similar.

The estimated elasticity of demand under ETC (which I denote $\eta_{\mathrm{ETC}}$ ) measures the change in demand - which is a function of the perceived toll change - as a function of the actual toll change; in other words, it measures $\frac{\partial q(\tilde{\tau})}{\partial \tau} \frac{\tau}{q(\tilde{\tau})}$, where $\tau$ denotes the actual toll, and $\tilde{\tau}$ denotes the perceived toll. We can decompose $\eta_{\mathrm{ETC}}$ as follows: 


$$
\underbrace{\frac{\partial q(\tilde{\tau})}{\partial \tau} \frac{\tau}{q(\tilde{\tau})}}_{\eta_{\mathrm{ETC}}}=\underbrace{\left[\frac{\partial q(\tilde{\tau})}{\partial \tilde{\tau}} \frac{\tilde{\tau}}{q(\tilde{\tau})}\right]}_{\eta} * \underbrace{\left[\frac{\partial \widetilde{\tau}}{\delta \tau} \frac{\tau}{\tilde{\tau}}\right]}_{\text {Elasticity of } \tilde{\tau} \text { wrt } \tau}
$$

Equation (4) indicates that the ratio of the estimated elasticity of demand under electronic toll collection $\left(\eta_{\text {ETC }}\right)$ to the underlying elasticity of demand $(\eta)$ gives the elasticity of the perceived toll $(\tilde{\tau})$ with respect to the actual toll ( $\tau$ ), or in other words, the extent of misperception of toll changes associated with ETC.

I use the estimated elasticity of demand under manual toll collection as a proxy for $\eta$. This is based on the assumption of a constant elasticity of demand curve, or at least an approximately constant elasticity within the range of the estimated toll increase so that the equilibrium change in tolls associated with ETC does not directly affect the elasticity. This also ignores any direct effect that ETC may have on the underlying demand for driving, an issue I investigate in more detail in Section 5.1. For this back of the envelope calculation, I use the results from column 4 of Table 4. For facilities that eventually adopt ETC, these results indicate a short run elasticity of driving under manual toll collection of -0.061 and of -0.007 at the average ETC penetration rate in my sample of $0.4(=-0.061+0.4 * 0.134) .{ }^{10}$ The ratio of the elasticities is therefore 0.11 .

These results imply that a given increase in the actual toll causes the perceived toll at the average ETC penetration rate to rise by only 11 percent as much as it would have under manual toll collection. Note that these results are not informative about whether in equilibrium the toll level is misperceived. As emphasized previously, the elasticity that I estimate is the short run elasticity, which is likely to decline in absolute value if a decline in tax salience reduces the fraction of individuals who observe the toll change, or increases the fraction of individuals who underestimate the magnitude of toll changes that are observed. It is possible, however, that even if individuals do not observe toll changes, they have unbiased expectations about the toll level so that the elasticity as a function of the expected tax does not change. I

\footnotetext{
${ }^{10}$ While it might be preferable to evaluate the elasticity under the steady state penetration rate of 0.6 , in practice this results in a positive (although statistically insignificant) elasticity of 0.019 , which creates conceptual problems for this exercise.
} 
present some suggestive evidence for this possibility in Section 5.2 below, where I examine the impact of the diffusion of ETC on traffic.

As discussed in Section 2, if the government lacks the ability to commit on policy, it will have an incentive to change taxes in response to even short run changes in the elasticity of demand. In simple models of tax setting such as the Ramsey model or the decisions of a profit maximizing government owned enterprise, the equilibrium tax rate should rise in proportion to the decline in the effective elasticity. Since I estimate the elasticity under ETC to be about 11 percent of that under manual toll collection, this suggests that the equilibrium toll should rise by about 9 fold. However, a government owned enterprise - such as a toll facility -may also place some weight on consumer surplus (Peltzman 1971, Baron and Myerson 1982, Timmins 2002). The enterprise's manager(s) want to maintain employment, which requires the satisfaction of its citizens. Citizens are shareholders in the government owned enterprise, and therefore benefit from profit maximizing prices. However, some or all of the citizens are also consumers of the publicly produced good, and therefore desire lower prices, which would place downward pressure on the profit maximizing price.

The objective of a government-owned enterprise may therefore be expressed (as in e.g. Timmins, 2002) as a weighted average of (net of payments) consumer surplus and profits:

$$
\max _{p} v \int_{p}^{\infty} D(x) d x+(1-v)(p-c) D(p)
$$

where $v \in[0,1]$ denotes the relative weight placed on consumer surplus. The government as a pure profit maximizer corresponds to $v=0, v=1 / 2$ implies that the government maximizes net social surplus (i.e. sets price equal to marginal cost) and $v=1$ implies that the government maximizes consumer welfare (i.e. sets price to zero). ${ }^{11}$ This objective function yields a modified inverse elasticity rule for price setting by a government owned enterprise:

\footnotetext{
${ }^{11}$ The qualitative insights are similar if the profit component of the objective function in equation (5) is replaced with some other standard government objective function such as raising a fixed amount of revenue subject to minimal distortion as in Ramsey (1927), correcting a Pigouvian externality, or maximizing revenue (i.e. leviathan
} 


$$
\frac{p-c}{p}=\frac{1}{\varepsilon}\left(\frac{1-2 v}{1-v}\right)
$$

where $\varepsilon$ is the absolute value of the elasticity of demand. The markup is decreasing in $v$, the relative weight that the enterprise places on consumer surplus. The magnitude of the tax increase in response to a decline in the short run elasticity is also declining in $v$.

We can use the estimated elasticity of demand under manual toll collection to make a back of the envelope calculation of the implied relative weight $v$ that toll operating authorities place on consumer surplus. Under the assumption of a zero marginal cost of toll collection equation (6) indicates that the estimated elasticity of -0.049 under manual toll collection (Table 4 , column 1 ) implies a relative weight on consumer surplus of 0.49 . This suggests that the toll authority's objective function comes very close to a net social surplus maximizer (i.e. $v=1 / 2$ ).

With a relative weight on consumer surplus of 0.49 , the first order condition for price setting of a government owned enterprise (equation 6) suggests that a decline in the short run elasticity to 11 percent of its previous level should be associated with an increase in the price of about 35 percent. This predicted increase is similar to the 36 to 38 percent increase in tolls estimated in the sample of facilities with no ETC discounts (see Table 2), which is the sample from which the change in elasticity was computed. While there is naturally a quite large implicit confidence interval around the predicted price increase, it is reassuring that the price increase implied by the estimated change in elasticity and the estimated weight the government places on consumer surplus is similar to the price increase estimated directly from the data.

\section{Alternative Explanations}

I have interpreted the evidence that the introduction of ETC is associated with an increase in the toll rate as the consequence of the decline in the visibility of tolls to consumers who pay for them electronically. In this section, I consider a number of alternative explanations for the increase in the toll 
rate associated with ETC. In particular, I consider the lower personal compliance costs of paying tolls under ETC (Section 5.1), the potential endogeneity of the timing of ETC adoption (Section 5.2), the lower operating costs of toll collection under ETC (Section 5.3), the capital outlays required for ETC installation (Section 5.4), and the potential change in menu costs associated with ETC (Section 5.5). I conclude that none of these alternative interpretations is likely to be able to explain the empirical findings.

\subsection{ETC lowers personal compliance costs of toll payment}

ETC reduces the compliance costs for drivers associated with paying tolls (Levinson 2002, p.52-53, Hau 1992). These compliance costs consist of both the queuing time caused by congestion at toll plazas and the time spent paying the toll in the toll plaza. Friedman and Waldfogel (1995) estimate that, under manual toll collection, compliance costs are about 15 percent of toll revenue. Under the generous assumption that ETC reduces compliance costs to zero, ETC would reduce average compliance costs in steady state (i.e. with 60 percent ETC penetration) from $15 \%$ of the monetary toll costs to $6 \%$ of the monetary toll costs, and would therefore reduce the total toll (monetary toll plus monetized compliance costs) by 8 percent. Of course, the compliance costs of manual toll collection are likely to be larger for drivers who choose to adopt ETC. Drivers who adopt ETC tend to be disproportionately higher income and likely to travel frequently on the facility (Amromin et al., 2005, Pietrzyk and Mierzejewsli 1993). An upper bound on the reduction in compliance costs would be to assume that drivers who do not adopt ETC face no compliance costs (e.g. they have a zero opportunity cost of time) and that adoption of ETC reduces compliance costs to zero. The reduction in compliance costs associated with ETC would then reduce the total toll by 15 percent. This suggests that the increase in the total toll associated with ETC is about 8-15 percentage points less than the estimated $20-40$ percent increase in the monetary toll associated with ETC.

Reductions in compliance costs may be part of the way that ETC reduces the visibility of tolls; less time spent queuing or paying tolls may reduce the salience of the toll. Indeed, as noted in the Introduction, reductions in the compliance costs of paying taxes - such as federal income tax withholding - are often opposed on the grounds that the reduced compliance costs make taxes less visible, and 
therefore encourage an increase in these taxes. However, reductions in the compliance costs of paying tolls may also directly affect demand for driving and hence the equilibrium toll rate. ${ }^{12}$ Three independent pieces of evidence, however, suggest that any reduction in compliance costs associated with ETC is unlikely to be the primary factor behind the estimated increase in toll rates associated with ETC.

\subsubsection{Back of the envelope calculation of effect of lower compliance costs on toll rates}

First, a rough back of the envelope calculations suggests that estimated increase in monetary tolls associated with ETC is probably several orders of magnitude too large to be explained solely by ETC's reduction in compliance costs. I assume that the monetary toll and the compliance costs are perfect substitutes from the drivers' perspective - so that the demand for driving is a function only of the total toll - and use a local linear approximation to the demand curve for driving. Under these assumptions, a profit maximizing toll authority would increase the toll rate by $\$ 0.50$ for every $\$ 1$ reduction in compliance costs. Once we take account of our estimate that toll authorities in fact maximize a weighted sum of profits and consumer surplus, with a relative weight on consumer surplus of 0.49 , the toll authority would be expected to raise the toll by $\$ 0.04$ for every $\$ 1$ reduction in compliance costs. ${ }^{13}$ The estimated reduction in compliance costs associated with ETC of about 8 to 15 cents per dollar of toll therefore suggests that the average toll authority in our sample would raise the toll by about $0.3-0.6$ percent. The expected increase in the monetary toll associated with ETC's reduction in compliance costs is therefore about two orders of magnitude smaller than the estimated 20 to 40 percent increase in the monetary toll associated with ETC.

\footnotetext{
${ }^{12}$ Relatedly, it is possible that the increase in demand for driving associated with ETC raises congestion and hence raises the optimal congestion tax. As a crude test of this I examined whether the analysis of the impact of ETC on the change in toll rates in equation (2) was sensitive to including the change in traffic as a control variable, and found that it was not.

${ }^{13}$ The operating authority chooses the toll rate $\tau$ to solve $\max _{\tau} v \int_{\tau}^{\infty} D(t+w) d x+(1-v)(\tau-c) D(t+w)$ where $w$ denotes the wait time (i.e. compliance) cost, and $v$ denotes the relative weight that the operating authority places on consumer surplus. The change in the equilibrium toll rate with respect to the compliance cost is therefore: $\frac{\partial \tau}{\partial w}=-\left[\frac{(1-2 v) D^{\prime}(\tau+w)+(1-v)(p-c) D^{\prime \prime}(\tau+w)}{(1-2 v) D^{\prime}(\tau+w)+(1-v)(p-c) D^{\prime \prime}(\tau+w)+(1-v) D^{\prime}(p+w)}\right]$
} 
Consistent with this back of the envelope calculation, two distinct pieces of empirical evidence suggest that there is no detectable increase in tolls in response to reductions in compliance costs. ${ }^{14}$

\subsubsection{Variation across roads in the reduction in compliance costs associated with ETC}

One piece of evidence comes from variation across roads in my sample in the compliance costs savings from ETC. This arises from variation in the number of times an individual must make a toll transaction (i.e. pay a toll or take a ticket) while driving the full length of a road, and hence variation in the toll compliance costs from a full length trip. For example, in 1985 an individual made 11 toll transactions while driving the length of the Garden State Parkway, compared to only two on the New Jersey Turnpike. If tolls are increased under ETC in response to the reductions in compliance costs, we might therefore expect these tolls increases to be higher on roads with a greater number of toll transactions, or a greater number of toll transactions per dollar of toll paid or per mile of road driven. In fact, there is weak evidence of the opposite.

Table 5 shows the results. Column 1 shows the baseline results when I re-estimate equation (2) on the sub-sample of facilities that are roads; it shows that the effect of ETC persists in the roads sub-sample. In columns 2 through 4 I repeat this baseline analysis but include interactions of both $\triangle E T C Y e a r$ and $\triangle E T C$ with a variable that measures of the compliance costs associated with toll collection on a full length trip in $1985 ;{ }^{15}$ I also include the main effect for the measure of compliance costs. Columns 2 through 4 show results for three different measures of the compliance costs associated with toll collection on a full length trip. In column 2 I measure compliance costs by the number of separate toll transactions involved in a full length trip on the road; on average it is 2.3. In column 3 I measure compliance costs as

\footnotetext{
${ }^{14}$ These two separate pieces of evidence come from distinct sources of variation in compliance costs in the subsample of facilities that are roads and in the sub-sample of facilities that are bridges and tunnels, respectively. Unfortunately, I do not have enough power in either subset of facilities to examine whether there is a relationship between changes in compliance costs and changes in the short run elasticity of demand for driving with respect to the toll. The analysis therefore focuses on the impact of changes in compliance costs on toll rates.

${ }^{15}$ I define this variable in 1985 , since the number of transactions is potentially affected by whether a facility has ETC. In practice, as discussed in Section 5.3, there is no evidence of an effect of ETC on the number of toll transactions. Not surprisingly, therefore, the analysis in Table 5 is not affected if I allow the number of transactions variable to be time varying (not shown). Data on the number of toll transactions come from toll operating authority websites, which include not only current information but histories of additions or removals of toll plazas.
} 
the number of transactions per dollar of toll; on average, someone driving a one way, full length trip on a road in my sample in 1985 made 1.5 transactions per dollar of toll paid. Finally, in column 4 I measure compliance costs by the number of transactions per mile in 1985; on average, there is a toll transaction every 22 miles for roads in my sample. For all three measures of compliance costs, the results suggest that the increase in tolls associated with ETC is in fact lower on roads with higher compliance costs; the coefficient on $\triangle E T C Y e a r *$ ComplianceCost is always negatively and, sometimes, statistically significant. This negative relationship is somewhat puzzling; it may reflect the higher menu costs associated with toll changes when there are more separate toll transactions to be changed per dollar of toll. Importantly, however, I am able to reject the prediction of the compliance cost story that the increase in tolls associated with ETC should be higher on roads where compliance costs are a greater share of the total toll.

\subsubsection{Reductions in compliance costs on bridges and tunnels from a change to one-way tolling}

Finally, a separate experiment in the data provides some independent evidence on the effect of compliance cost reductions on the equilibrium toll rate. During my sample, just over half of the bridges and tunnels (40 out of 79) switched from collecting tolls on both ends of the facility to collecting tolls only at one end; Figure 3 shows the distribution of change dates for these facilities. A change from bothway to one-way tolling should cut compliance costs - as well as administrative costs - of toll collection in half. This reduction in compliance costs is of similar magnitude to a the reductions in compliance costs associated with steady state ETC penetration; it therefore provides an opportunity to gauge the impact of such reductions in compliance costs on toll rates. Of course, it is possible that the change to one-way tolling also affects the salience of tolls; it is not clear, for example, if paying 50 cents twice is more or less salient than paying \$1 once. Therefore, a priori, evidence of an impact on toll rates is not necessarily a problem for a salience story. However, the absence of an effect would help assuage concerns that the estimated impact of ETC on toll rates stems from its effect on reducing compliance costs of driving. 
I limit the sample to bridges and tunnels, since these are the facilities "at risk" for changing from twoway to one way tolling. ${ }^{16}$ Table 6 shows the results. They suggest little - if any - increase in tolls associated with a switch from two-way to one-way tolling, and the associated reductions in compliance costs of toll paying. Recall that the tolls on bridges and tunnels are defined as the tolls on a round trip, so that there is no mechanical effect on tolls from changing from two-way to one-way tolling. Column 1 replicates the basic analysis of the increase in tolls associated with ETC from estimation of equation (2); it shows that the effect of ETC persists in the bridges and tunnels sub-sample. In column 2, I add an additional right hand side indicator variable for whether it is the year in which the facility switched from two-way to one-way tolling ( $\Delta$ ToOneWay ${ }_{i t}$ ). Unlike ETC whose use diffuses over time and whose effects on toll rates is therefore expected to occur incrementally over time, the switch to one-way tolling is instantaneous, and therefore any effect on toll rates might also be expected to be instantaneous. The coefficient on $\Delta$ ToOneWay ${ }_{i t}$ is 0.041 (s.e. $=0.035$ ) which suggests that the change from both-way to one-way tolling is associated with a statistically insignificant 4.1 percent increase in tolls. Under the same assumptions as in the previous back of the envelope calculation, a reduction in compliance costs by $50 \%$ (i.e. from $15 \%$ of tolls to $7.5 \%$ of tolls) would be expected to increase the toll rate of a profit maximizing monopolist by about 3.8 percent, and by a toll authority with a relative weight on consumer surplus of 0.49 by about 0.3 percent; neither response can be rejected by my estimates, nor can my estimates reject the hypothesis of no increase in tolls in response to this reduction in compliance costs. By contrast, the coefficients on $\triangle E T C$ and $\triangle E T C Y e a r$ in column 2 together imply that after ETC has diffused to its steady state level, it is associated with a statistically significant increase in toll rates of 36 percent $\left(\sim \exp \left(\beta_{\triangle \mathrm{ETC}}+14 * \beta_{\triangle \mathrm{ETCYEAR}}\right)\right)$. I can reject that the implied steady state effect of ETC is the same as that from the switch to one-way tolling at the $90 \%$ confidence level.

\footnotetext{
${ }^{16}$ There are actually two roads that switched to one way tolling, although I ignore them for purposes of this analysis. The Hampton Toll Plaza on the Blue Star Turnpike in NH had brief experiments with one way tolling in Sept-Oct 2003 and July October 2004; The John F. Kennedy Memorial Highway in MD switched to one-way tolling in 1991.
} 
Of course, it is possible that there is a lag before the change to one-way tolling has its full effect on toll rates. For example, politicians might find it easier to phase in a toll increase gradually. In column 3, therefore, I add an indicator variable for whether the facility had previously switched from two-way to one way tolling ( $\Delta$ ToOneWayYear ${ }_{i t}$ ), so that the specification is now symmetric to that used to gauge the effects of ETC. The coefficient on $\triangle T$ ToOneWay ${ }_{i t}$ attenuates in magnitude and remains statistically insignificant, and the coefficient on $\Delta$ ToOneWayYear ${ }_{i t}$ is statistically insignificant; by contrast, there continuous to be a statistically significant coefficient on $\triangle E T C Y e a r$; I do not, however, have enough power to reject that the coefficients on $\triangle E T C Y e a r$ and $\triangle T o O n e W a y Y e a r_{i t}$ are statistically distinguishable.

\subsection{Endogeneity of the timing of ETC adoption}

The timing of a facility's ETC adoption may be spuriously correlated with the need to raise tolls. For example, facilities may respond to increased congestion by both adopting ETC and raising tolls as complementary congestion-reducing strategies. This suggests we should observe increases in congestion on a facility (or a proxy for it such as traffic) prior to ETC adoption. Alternatively, facilities might respond to a negative revenue shock by both raising tolls and adopting ETC, with the latter a way to lower revenue losses from the administrative costs of toll collection. This suggests we should observe declining revenue (or declining traffic) on a facility in the years prior to ETC adoption. More generally, we can look for changes in toll rates in the years prior to ETC adoption as a partial test of the identifying assumption that absent the adoption of ETC a facility would not have experienced differential changes in its toll rate. Of course, if the lower salience of ETC makes it easier to raise tolls, ETC might be adopted precisely by facilities that are encountering difficulties in making needed toll adjustments, suggesting that facilities might experience declines in traffic, revenue or toll increases prior to ETC adoption. While evidence of such effects is therefore not necessarily inconsistent with the salience story, the lack of any such evidence reduces concerns about omitted variable bias and spurious findings. 
The results in Table 7 help alleviate these endogeneity concerns. I re-estimate equation (2) for three different dependent variables: $\Delta \log (\text { traffic })_{\text {it }}\left(\right.$ columns 1 and 2), $\Delta \log (\text { revenue })_{\text {it }}($ columns 3 and 4$)$, and $\Delta \log (\text { minimum toll })_{\text {it }}$ (columns 5 and 6). All regressions include $\triangle E T C$ and $\triangle E T C Y e a r$, as well as year fixed effects. I also include an indicator variable for whether it is 1 to 2 years prior to ETC Adoption (odd columns) or whether it is 1 to 5 years prior to ETC adoption (even columns). The coefficients on these indicator variables for years just prior to ETC adoption show no statistically or substantively significant evidence of systematic changes in traffic, revenue or tolls in the years prior to a facility's adopting ETC. One reason why these endogeneity concerns may not in practice be a problem is that, as noted above, the different facilities run by a given operating authority tend to all adopt ETC at the same time, and yet may be experiencing different patterns of traffic and tolls.

The results in Table 7 also suggest that revenue increases by about 3 percent each year after ETC is installed. This is consistent with my findings that ETC is associated with an increase in toll rates, and that demand for driving is very inelastic with respect to the toll. For the sample for which I have revenue data, I estimate that ETC is associated with a 2.2 percent increase in tolls each year (not shown).

The results in Table 7 also suggest that traffic declines in the years after ETC is installed, although these estimates are not statistically significant and are substantively quite small. A decline in traffic would be consistent with the rational expectations model discussed in Section 2 in which individuals using ETC do not directly observe toll changes but form unbiased expectations about toll levels. Since tolls rise under ETC, if individuals have unbiased expectations about the toll rate this should cause traffic to decline in equilibrium. If ETC also increases the demand for driving, this could cause traffic to rise; the fact that traffic does not appear to rise however suggests that any such direct demand effect of ETC is not enough to offset the effect of the higher perceived toll rates.

As a separate test of whether the decision to adopt ETC is correlated with (unobserved) shocks to revenue needs, I also examined whether ETC is associated with changes in other highway user taxes. In the mid-1980s, revenue for tolls make up only about $10 \%$ of total state and local highway user fees; gasoline taxes and motor vehicle registration fees are other important sources of revenue from highway 
users (US Department of Transportation 1985, 1986). I find no evidence that ETC is correlated with changes in state gas tax rates, tax revenues from all motor fuels, or state tax revenues from motor vehicle registration and drivers' licenses (results not shown). ${ }^{17}$ The fact that ETC is not associated with increases in these other highway user taxes helps alleviate concerns that ETC adoption is correlated with unobserved increases in revenue demand. The fact that ETC is not associated with decreases in these other highway user taxes suggests that ETC is associated with an increase in total highway revenue (of about the same magnitude as the increase in toll rates, given how inelastic demand is).

\subsection{ETC lowers the operating cost of toll collection}

ETC is associated with substantial reductions in the annual costs of operating and maintaining toll facilities (Pietrzyk and Mierzejewski 1993, Hau 1992, Levinson 2002 and cites therein). For example, Pietrzyk and Mierzejewski (1993, p.23) estimate that operating and maintenance costs per lane are at least 90 percent lower under electronic toll collection than under manual toll collection. The cost savings arise primarily from reductions in the labor costs associated with toll collection.

Although Becker and Mulligan (2003) show that increases in the efficiency of tax collection can increase the equilibrium tax rate, this requires an improvement in the marginal efficiency of tax collection. By contrast, ETC improves the fixed component of the efficiency cost of taxation, since the ETC administrative cost savings are independent of the toll rate charged. This decline in fixed administrative costs of tax collection should therefore not prompt an increase in the rate of existing taxes. $^{18}$

A decline in the fixed administrative costs of tax collection could, however, encourage the introduction of new taxes. For example, lower fixed administrative costs of toll collection might encourage the introduction of tolls on roads that had not been previously been tolled or the construction of

\footnotetext{
${ }^{17}$ These results come from estimation of equation (2) at the state level, using changes in log tax revenue or log tax rate for various state taxes as the dependent variable. To measure ETC_Year at the state level, I use how many years it has been since any facility in the state has ETC. This state-level specification yields similar estimates of the increase in toll revenue associated with ETC as the facility-level analysis shown in Table 7. I am grateful to John Rork for providing the data on state tax rates and tax revenues.

${ }^{18}$ Note moreover that if operating authorities set tolls to meet an exogenous revenue requirement, the reduction in administrative costs would lower the equilibrium toll needed to raise a fixed amount of (net) revenue.
} 
new (tolled) roads where no road existed before. Any such effects of ETC, however, would not show up in my analysis, which limits the sample to facilities with pre-existing tolls. Lower fixed administrative costs of toll collection could also encourage the installation of more toll collection points on an existing toll facility; however, I find no evidence that ETC had such an effect. ${ }^{19}$ The increase in tolls associated with ETC therefore reflects increases in existing tax rates, which cannot be explained by declines in the fixed administrative costs of tax collection. Of course, as previously mentioned, there is some suggestive evidence that ETC is associated with a decline in the probability of the toll being set to zero; while this could potentially be explained by lower fixed administrative costs, this does not contribute to my estimated increase in tolls associated with ETC since such cases are censored.

\subsection{ETC installation requires capital outlay}

Although ETC lowers the costs of operating and maintaining toll facilities, installation of ETC requires a capital outlay, which could require an increase in tolls. This seems unlikely, since operating authorities can borrow to cover these capital costs and since capital costs are recouped within a few years by the savings in operating and maintenance costs, and by revenue from the sale or lease of the transponders and interest on prepayments and deposits (Pietrzyk and Mierzejewski 1993, Hau 1992). Of course, it is possible that operating authorities might use the installation costs of ETC as an excuse to raise tolls, even though ETC is self-financing. Any such excuse might be used for a one-time increase in tolls when ETC comes in; it seems less natural that this excuse could be used for subsequent increases in tolls as ETC use diffuses among drivers.

\subsection{Changes in menu costs associated with ETC}

Finally, it is possible that ETC might lower the administrative cost of toll changes (i.e. menu costs). For example, there might be literal menu cost savings if signs listing the toll rate do not have to be changed as they do for manual tolls. Alternatively, ETC might allow flexibility for smaller increases of

\footnotetext{
${ }^{19} \mathrm{I}$ re-estimate equation (2) using as a dependent variable a binary measure for whether there is an increase in the number of toll transactions someone driving a one-way, full-length trip on the facility would have to make. I perform this analysis both for the full sample of facilities and separately for the roads sub-sample and for the bridges and tunnels sub-sample.
} 
non "round" amounts; unlike manual tolls, this would not impose on drivers that they carry small coins. In practice, however, ETC tolls are not less "round" than manual tolls, except when they are specified as a fixed percent discount off of the manual toll. In addition, the effect of ETC on toll rates persists for the sub-sample of facilities that do not offer an ETC discount. For these facilities, there can be no menu cost savings as changing the electronic toll requires changing the manual toll, and all facilities continue to have at least some manual payers. Finally, even if ETC did reduce menu costs, this should suggest that ETC would be associated with more frequent toll adjustments but it is not clear why this would produce a higher equilibrium toll rate.

\section{Conclusion}

This paper has examined the hypothesis that a less salient tax system can produce a higher equilibrium tax rate. Belief in this possibility has contributed to opposition to tax reforms that are believed to reduce tax salience, such as Federal income tax withholding or a partial replacement of the income tax with a value-added tax. Yet the sign of the effect of tax salience on tax rates is theoretically ambiguous, and empirical evidence has been lacking.

I examine the relationship between tax salience and tax rates empirically by looking at the impact of the adoption of electronic toll collection (ETC) on toll rates. Because the driver no longer plays an active, physical role in each toll payment, toll rates may be less salient under electronic toll collection than under manual toll collection. To analyze the impact of ETC, I collected a new data set on toll rates over the last half century on 123 toll facilities in the United States. Since different tolls facilities adopted electronic toll collection in different years, and some have not yet adopted it, I am able to examine the within-toll facility change in tolls associated with the introduction of electronic toll collection.

I find robust evidence that toll rates increase following the adoption of electronic toll collection. These estimates suggest that after ETC use among drivers has diffused to its steady state level, toll rates are 20 to 40 percent higher than they would have been under manual toll collection. Consistent with the hypothesis that ETC increases toll rates because it reduces the salience of the tax system, I also find that the short run elasticity of driving with respect to the actual toll declines (in absolute value) under ETC. I 
consider a variety of alternative explanations for this finding - such as the effect that electronic toll collection may have on toll collection administrative costs or on drivers' willingness to pay for access to the facility - and conclude that these alternatives are unlikely to be able to explain the increase in toll rates associated with electronic toll collection.

Given the theoretical ambiguity of the sign of the effect of tax salience on tax rates, my findings leave open the question of how changes in the visibility of other tax systems - such as income tax withholding or requirements to post VAT-inclusive prices - affect these equilibrium tax rates. In light of the findings of this paper, I consider such questions an interesting and important direction for future work. 


\section{References}

Acemoglu, Daron and James Robinson. 2002. "Inefficient Redistribution”. American Political Science Review 95: 649-61.

Amromin, Gene, Carrie Jankowski, and Richard Porter. 2005. "Transforming Payment Choices by Doubling Fees on the Illinois Tollway." Unpublished mimeo.

Baron, David and Roger Myerson. 1982. "Regulating a Monopolist with Unknown Costs." Econometrica 50: $911-930$.

Barro, Robert and David Gordon. 1983. "A Positive Theory of Monetary Policy in a Natural Rate Model.” Journal of Political Economy 91(4): 589-610.

Becker, Gary and Casey Mulligan. 2003. "Deadweight costs and the size of government." Journal of Law and Economics, XLVI: 293 - 340.

Brennan, Geoffrey and James Buchanan. 1980. "The power to tax: Analytical foundations of a fiscal constitution." Cambridge University Press, Cambridge.

Buchanan, James and Richard E. Wagner. 1977. Democracy in Deficit. NY: Academic Press.

Buchanan, James. 1967. "Public Finance in Democratic Process."

Chetty, Raj, Kory Kroft and Adam Looney. 2006 "Bounded Rationality, Salience, and Taxation: Theory and Evidence from a Field Experiment." Unpublished mimeo.

Dollery, Brian and Andrew Worthington. 1996 "The empirical analysis of fiscal illusion", Journal of Economic Surveys, 10, pp. 261-298.

Dusek, Libor. 2003. "Do Governments Grow When they Become More Efficient? Evidence from Tax Withholding." Unpublished PhD Dissertation, University of Chicago.

Feldman, Naomi and Peter Katuscak. 2005. “Should the Average Tax Rate by Marginalized?” Mimeo. http://econ.bgu.ac.il/facultym/nfeldman/WPapers/Should_the_Average_Tax_Rate_Be_Marginalized.pdf

Friedman, David and Joel Waldfogel. 1995. "The Administrative and Compliance Cost of Manual Highway Toll Collection: Evidence from Massachusetts and New Jersey.” National Tax Journal, June.

Friedman, Milton and Rose Friedman. 1998. “Two Lucky People.” University of Chicago Press.

Hau. Timothy. 1992. "Congestion Charging Mechanisms for Roads: An Evaluation of Current Practice" World Bank Research Paper 1071. Washington: The World Bank, December.

Kearney, Melissa. 2005. "The Economic Winners and Losers of Legalized Gambling”. National Tax Journal. June.

Kydland, Finn and Edward Prescott. 1977. "Rules rather than direction: The inconsistency of optimal plans." Journal of Political Economy, 85, 473-490.

Levinson, David. 2002. "Financing Transportation Networks." 
Liebman, Jeffrey and Richard Zeckhauser. 2004. "Schmeduling". Unpublished mimeo. Available at http://www.ksg.harvard.edu/jeffreyliebman/schmeduling.pdf

Mirrlees, James. 1971. "An exploration in the theory of optimum income taxation." Review of Economic Studies 38(2): 175-208.

Pietrzyk, Michael and Edward Mierzejewski. 1993. "Electronic Toll and Traffic Management Systems." Washington DC, National Academy Press.

Oates, Wallace. 1988. "On the nature and measurement of fiscal illusion: a survey." In Geoffrey Brennan et al (eds) "Taxation and Fiscal Federalism: Essays in Honour of Russell Mathews", pp. 65-82. Sydney: Australian National University Press

Peltzman, Sam. 1971. "Pricing in Public and Private Enterprises: Electric Utilities in the United States." Journal of Law and Economics 14(1): 109-147.

Ramsey, Frank. 1927. “A Contribution to the Theory of Taxation.” Economic Journal 37: 47-612.

Sappington, David E.M. and J. Gregory Sidak. 2003. "Incentives for Anticompetitive Behavior by Public Enterprises." Review of Industrial Organization 22: 183 - 206.

Slemrod, Joel. 1996. "Which is the Simplest Tax System of Them All?" in Hank Aaron and William Gale (eds.) "The Economics of Fundamental Tax Reform" The Brookings Institution, pp. 355 - 391.

Timmins, Christopher. 2002. "Measuring the dynamic efficiency costs of regulators' preferences: Municipal water utilities in the arid west." Econometrica 70(2): 603 - 629.

The President's Advisory Panel on Federal Tax Reform. 2005. "Simple, Fair, and Pro-Growth: Proposals to Fix America's Tax System.” U.S. Government Printing Office, Washington D.C.

U.S. Census Bureau. 1985. "Annual Survey of State and Local Government Finances and Census of Governments."

U.S. Department of Transportation, various years. "Highway Statistics, YEAR.”

Wilson, John. 1990. "Are efficiency improvements in government transfer policies self-defeating in political equilibrium?" Economics and Politics 2 (3): 241 - 258. 


\section{Appendix A: Construction of toll data set}

\section{A.1 Sample}

The target sample is all publicly owned toll facilities in the United States (excluding ferries) that were charging a toll in 1985. I identified the target sample as the universe of toll facilities from the 1985 and 1986 volumes of "Highway Statistics" published by the U.S. Department of Transportation. In a few instances, I added facilities to the data that did not appear independently in the "Highway Statistics" volumes but that were disaggregated for us by the operating authority when we contacted them (such as the "Bee Line East Expressway" which is part of the "Florida Turnpike System" in "Highway Statistics").

The target sample consists of 183 toll facilities run by 88 operating authorities in 31 states. Of these, I was able to collect the requisite data for 123 facilities run by 49 operating authorities in 22 states. For the acquired facilities, opening dates range from 1924 to 1985, with a median opening date of 1955. All of the facilities in the sample started charging tolls on the opening date.

Appendix Table A1 provides some summary statistics on the 123 facilities in the sample. Specifically, it lists for each state and operating authority, the facilities for which I collected data, the date the facility started charging tolls, the date my toll data start (if later than the toll start date), the date (if any) at which the facility adopted Electronic Toll Collection (ETC), and whether the facility ever offered a discounted toll rate to ETC users. For purposes of the analysis, I defined two additional "states" ("New Jersey Pennsylvania and New York - New Jersey") to reflect the few cases of operating authorities that were jointly under the purview of the two states. The sample for analysis therefore consists of 24 state-like entities, as reflected in Table A1.

Appendix Table A2 provides a list of the 60 facilities in the target sample for which we were unable to find data. Not surprisingly, a factor that is strongly predictive of a lack of success in getting toll data is that the facility is no longer charging a toll toward the end of our sample period. Only half of the facilities that we were unable to collect data for were still charging tolls in 2003, compared to over 90 percent of the facilities for which I was able to collect data. Of the 9 states in which I was unable to collect data on any target facilities, 4 (CT, IA, MN, and WA) were no longer charging tolls in 2003. For facilities that were no longer charging tolls by the end of out sample period, I was usually unable to find any contact information, particularly if the operating authority that managed that facility no longer had any toll charging facilities. (Indeed, 8 out of the 13 facilities that were not charging a toll in 2003 that I was able to collect data for were managed by operating authorities that still had other facilities charging tolls). For the vast majority of facilities for which I am missing data that were still charging tolls at the end of our sample period, I contacted the relevant operating authority repeatedly but was unable to obtain the necessary data; in a very few of these cases, I was unable to find the relevant contact information. ${ }^{20}$ Another noticeable pattern in success in data collection is that we are missing data on all 12 target facilities in TX (even though all but 1 of the 10 operating authorities were still running facilities charging tolls by the end of the sample period). The TX operating authorities either did not respond to inquiries or did not provide sufficient data (despite multiple requests) to be included in the analysis.

The missing facilities raise questions about the validity of analyzing the impact of ETC on only a subsample of toll facilities. To the extent that the missing data is related to systematic geographic characteristics - such as the lack of any data on TX - we may wish to interpret the results as applicable only in certain states. A potentially more major concern is the selection on the dependent variable. As

\footnotetext{
${ }^{20}$ These were: the White County Bridge Commission, the Indiana Transportation Finance Authority, the Bellevue Bridge Commission, and the Roma International Toll Bridge.
} 
noted, facilities that are no longer charging tolls are much less likely to be in the sample. However, this likely biases my analysis against finding an effect of ETC on toll increases as facilities that are no longer charging tolls (and are therefore not experiencing any toll increases by definition) are much less likely to have adopted ETC. Indeed, only 1 of the 15 facilities in the acquired sample that had stopped charging a toll by 2005 had ever adopted ETC.

\section{A.2 Variable definitions}

ETC Penetration: I define the ETC Penetration rate as the fraction of toll transactions or the fraction of toll revenue collected by ETC. The definition of ETC penetration varies across (but not within) facilities depending on whether I could obtain more years of data for the fraction of toll transactions or the fraction of toll revenue paid for by ETC. These measures may differ because of ETC discounts. Where I observe both, the correlation is 0.90. For over 95 percent of facilities, ETC penetration is defined based on all toll revenue (or transactions); in a few cases it refers to just passenger car revenue (or transactions). For about two-thirds of facilities ETC penetration was reported separately for each facility. For the others, it was reported for the entire operating authority; for these, I impute to each facility-year the operating authority - year average. Since, as discussed, adoption of ETC is almost always simultaneous on facilities within an operating authority, this should be a reasonable approximation.

Tolls: Tolls are defined as the nominal toll rate for passenger cars; high frequency discounts (i.e. commuter discounts) are not coded. I collected data on both the "manual" (i.e. cash) toll rate and the discounted electronic toll rate, if offered. I define the toll on bridges, tunnels, or causeways as the roundtrip cost on that facility; I use the round-trip rate because 40 of the 79 bridges and tunnels changed from collecting a toll on both ends of the bridge to only collecting it on one end during the sample period. I define the toll rate on a road as the cost of a full length trip on this road. Where the road has several potential branches (such as the PA turnpike), I code a full length trip as the length on the mainline; where a road forks at one end (such as the New Jersey Turnpike), I code the full length trip as the longer fork. One potential concern with this definition is that it may fail to capture some toll changes on a road. Specifically, toll changes will be missed if they occur on uncoded branches (such as branches of the PA turnpike other than the mainline), on exit or entrance ramps along the road, or on non full-length routes within a ticket system (such as the New Jersey turnpike). In practice, I determined that this is unlikely to have any effect on my analysis. I constructed an indicator variable "any toll increase" that is coded if the road has a toll change on the coded toll or an unrecorded toll change for any of the reasons just discussed. I find that the analysis of the impact of ETC on the probability of a toll increase yields literally the same point estimates and standard errors when this variable is used instead of the standard binary variable for a coded toll increase; this is not surprising, given that the correlation between "any toll increase" and the standard binary variable for a recorded toll increase is 0.98 on roads.

As noted in the text, 15 of the 123 toll facilities that are charging a toll in 1985 subsequently set the toll to zero. These facilities (and the date that the toll is set to zero) are as follows: Astoria-Pt. Ellice Bridge (1993), Bluegrass Parkway (1991), Coronado Bridge (2002), Cumberland Bridge (2003), Daniel Boone Parkway (2003), Jackson Purchase Parkway (1992), Mt. Hope Bridge (1998), Murray Road Toll Bridge (2000), Navarre Bridge (2004), Norfolk-Virginia Beach Toll Road (1995), Pennyrile Parkway (1992), Rock Island Centennial Bridge (2003), Torras Causeway (2004), Vincent Thomas Bridge (2001), and Western Kentucky Parkway (1986). All of these facilities keep the toll at zero through 2005. However, it does not appear that a toll set to zero is always an absorbing state. Two facilities that set tolls to zero prior to 1985 subsequently reintroduced positive tolls: Antioch Bridge (reintroduced a toll in 1978) and Carquinez Bridge (reintroduced a toll in 1957). I treat all facility-years with zero tolls as censored in the analysis. As noted in the text, this may bias the estimated effect of ETC downward, as facilities are less likely to set tolls to zero when they have ETC; indeed of the 15 facilities that set their tolls to zero, only the Navarre Bridge adopted ETC and subsequently set the toll rate to zero. 
Traffic and revenue: For over 95 percent of facilities, the data pertain to all toll revenue or toll traffic; in a few cases they pertain only to passenger cars. Traffic and revenue data are all reported at the facility level, except for the three facilities in the New Hampshire Department of Transportation and for the three facilities in the Illinois State Toll Highway Authority for which they are reported at the level of the operating authority. For these, I assign the operating authority value to each facility within it. 


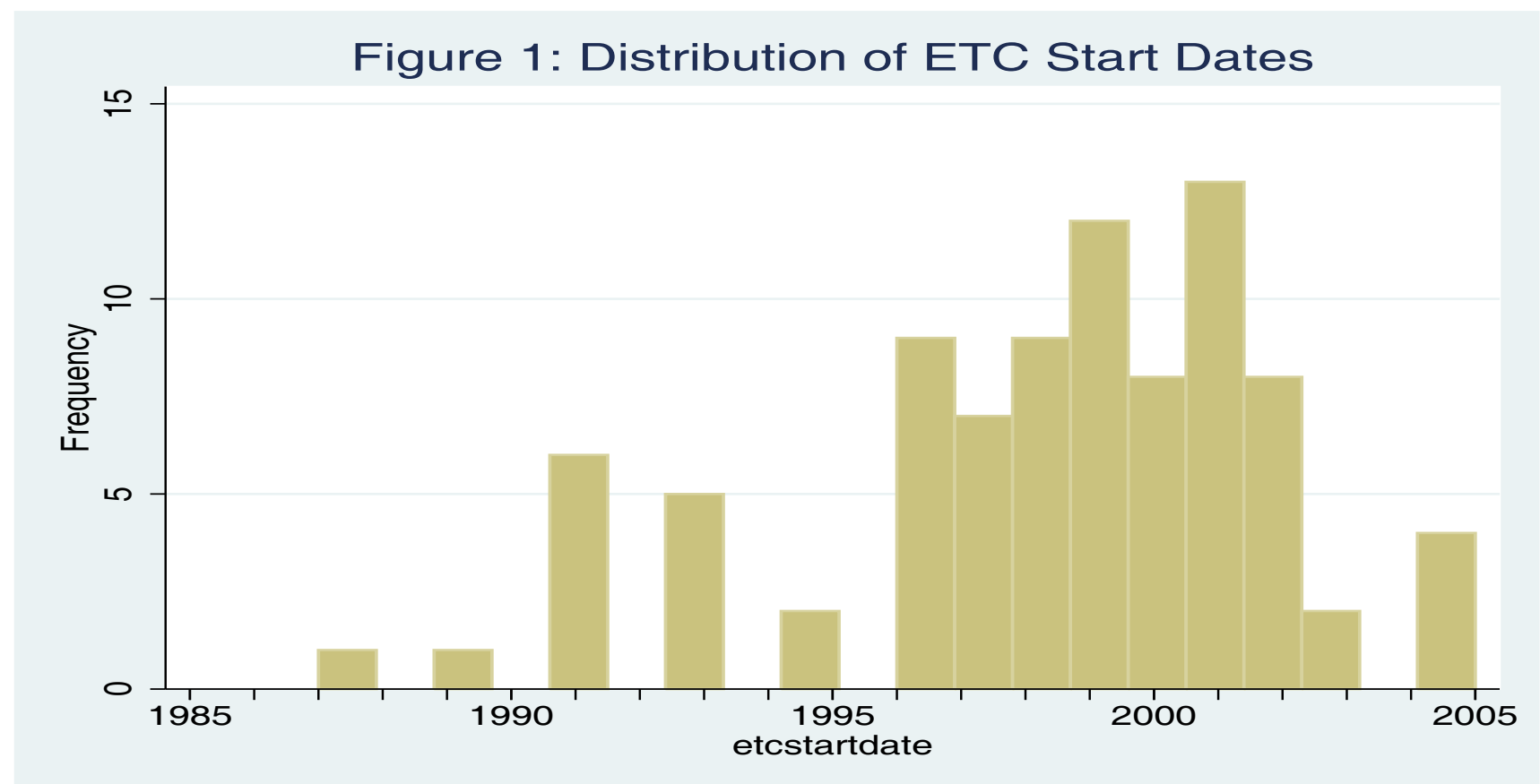

Figure 2: Within-Facility ETC Diffusion

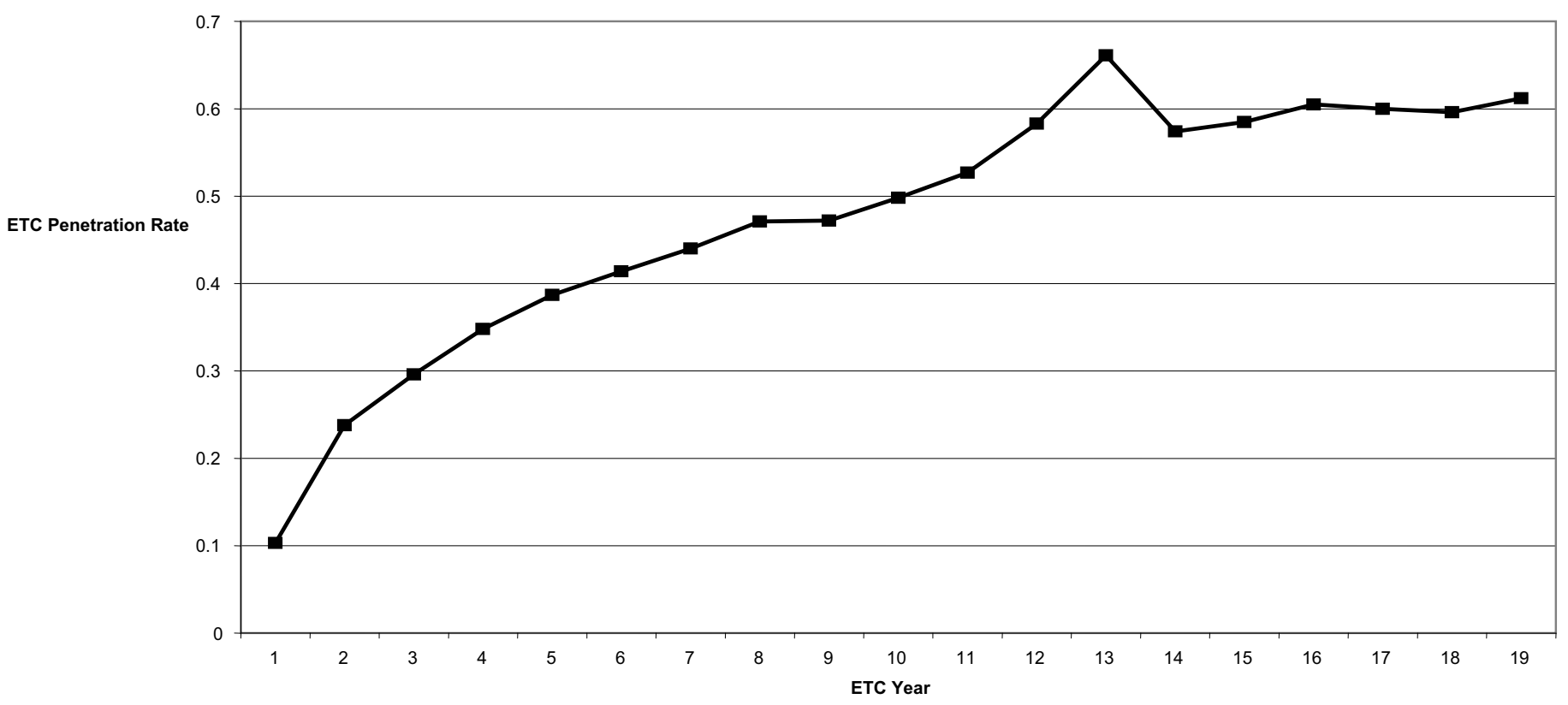

Note: Figure 2 reports the coefficient on indicator variables for the number of years a facility has had ETC from the following regression: ETC_Penetration ${ }_{i t}=\alpha_{i}+\sum_{k=1}^{19} \beta_{k} \mathbf{1}($ ETCyear $=k)$ where the $\alpha_{i}$ are facility fixed effects, $\mathbf{1}\left(\right.$ ETCyear $=\mathrm{k}$ ) are indicator variables for whether it is the $\mathrm{k}^{\text {th }}$ year of ETC, and ETC_Penetration is defined either as percent of transactions paid by ETC or percent of revenue paid by ETC, depending on the facility. 
Figure 3: Switching from Two-Way to One-Way Tolling

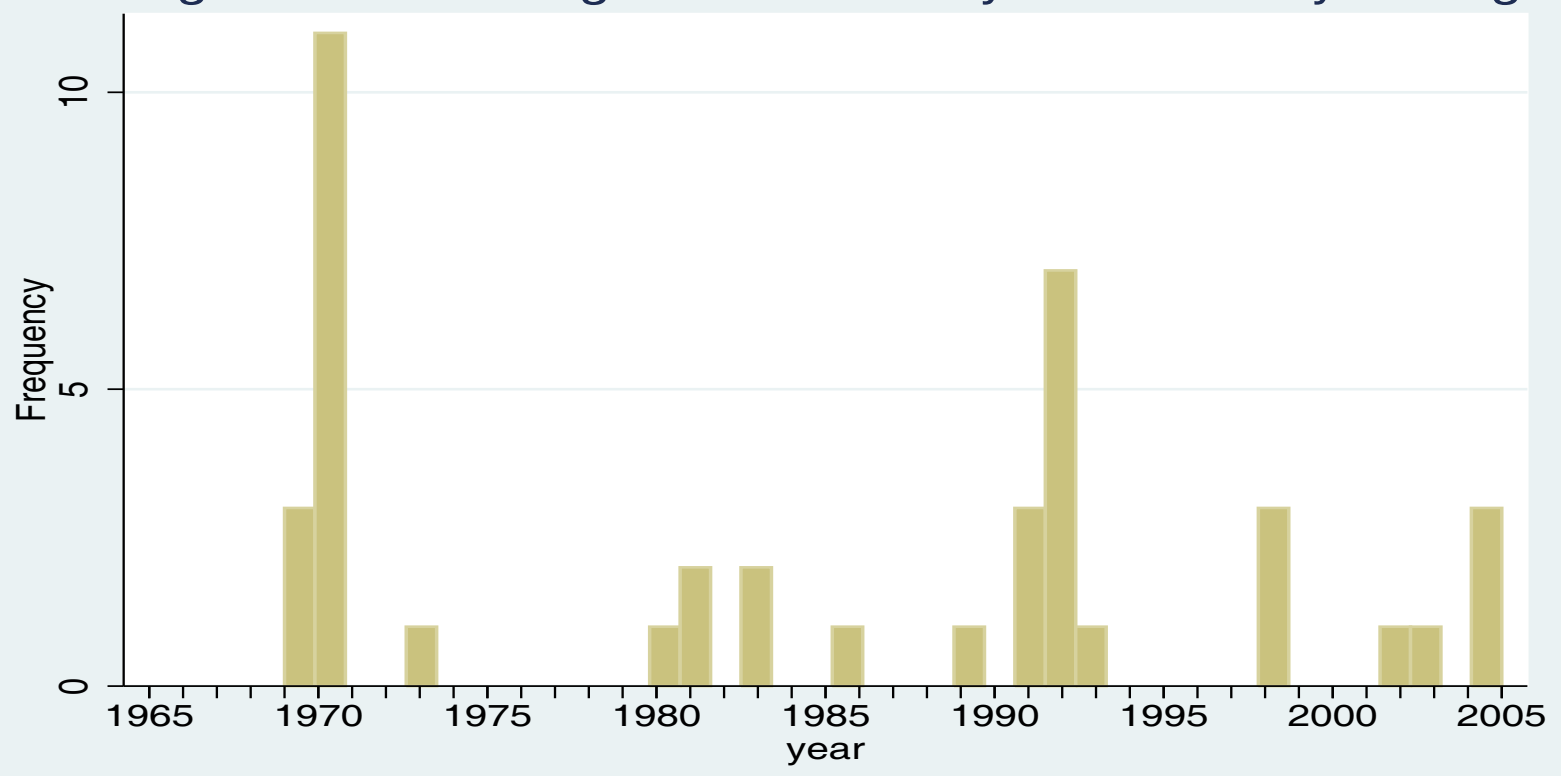


Table 1: Which facilities adopt ETC?

\begin{tabular}{lll}
\hline \hline & Probability adopt ETC by 2005 & $\begin{array}{l}\text { Average adoption date } \\
\text { conditional on adoption }\end{array}$ \\
\hline $\begin{array}{l}\text { Facility type } \\
\quad \text { Roads } \\
\text { Bridges or Tunnels }\end{array}$ & 0.76 & 1996.5 \\
& 0.52 & 2000 \\
Region of Country & & \\
$\quad$ Northeast & 0.70 & 1999.1 \\
Midwest & 0.58 & 1998.5 \\
South & 0.65 & 1996.4 \\
$\quad$ West & 0.30 & 2000.4 \\
\hline \hline
\end{tabular}

Note: Based on ETC adoption dates from 88 facilities. See text for more details.

Table 2: Impact of ETC on Toll Rates.

\begin{tabular}{|c|c|c|c|c|c|c|c|}
\hline & $\begin{array}{l}\Delta \log \\
\text { Min. Toll } \\
(1)\end{array}$ & $\begin{array}{l}\Delta \text { Log } \\
\text { Manual Toll } \\
(2)\end{array}$ & $\begin{array}{l}\Delta \log \\
\text { Toll } \\
(3) \\
\end{array}$ & $\begin{array}{l}\Delta \log \\
\text { Toll } \\
(4) \\
\end{array}$ & $\begin{array}{l}\Delta \log \\
\text { Min. Toll } \\
(5)\end{array}$ & $\begin{array}{l}\Delta \log \\
\text { Min. Toll } \\
(6) \\
\end{array}$ & $\begin{array}{l}\text { Does Min. Toll } \\
\text { Increase? (Binary) } \\
(7)\end{array}$ \\
\hline$\Delta$ ETCYear $_{\text {it }}$ & $\begin{array}{l}0.015 \\
(0.006) \\
{[0.018]}\end{array}$ & $\begin{array}{l}0.020 \\
(0.006) \\
{[0.004]}\end{array}$ & $\begin{array}{l}0.024 \\
(0.012) \\
{[0.061]}\end{array}$ & & & & $\begin{array}{l}0.073 \\
(0.024) \\
{[0.006]}\end{array}$ \\
\hline $\begin{array}{l}\Delta \text { ETC }_{-} \\
\text {Penetration }_{\text {it }}\end{array}$ & & & & $\begin{array}{l}0.623 \\
(0.285) \\
{[0.044]}\end{array}$ & $\begin{array}{l}0.557 \\
(0.262) \\
{[0.045]}\end{array}$ & $\begin{array}{l}0.501 \\
(0.261) \\
{[0.067]}\end{array}$ & \\
\hline$\Delta \mathrm{ETC}_{\mathrm{it}}$ & $\begin{array}{l}-0.051 \\
(0.035) \\
{[0.158]}\end{array}$ & $\begin{array}{l}0.016 \\
(0.032) \\
{[0.622]}\end{array}$ & $\begin{array}{l}-0.033 \\
(0.019) \\
{[0.097]}\end{array}$ & $\begin{array}{l}-0.051 \\
{[0.035]} \\
{[0.166]}\end{array}$ & $\begin{array}{l}-0.105 \\
(0.109) \\
{[0.348]}\end{array}$ & $\begin{array}{l}-0.097 \\
(0.108) \\
{[0.380]}\end{array}$ & $\begin{array}{l}-0.070 \\
(0.068) \\
{[0.315]}\end{array}$ \\
\hline $\begin{array}{l}\text { Mean dep. var } \\
\text { \# of states } \\
\text { \# op. author } \\
\text { \# facilities } \\
\mathrm{N} \\
\text { Estimation }\end{array}$ & $\begin{array}{l}0.020 \\
24 \\
49 \\
123 \\
5,079 \\
\text { OLS }\end{array}$ & $\begin{array}{l}0.022 \\
24 \\
49 \\
123 \\
5,079 \\
\text { OLS }\end{array}$ & $\begin{array}{l}0.017 \\
17 \\
31 \\
70 \\
2,875 \\
\text { OLS }\end{array}$ & $\begin{array}{l}0.017 \\
17 \\
31 \\
70 \\
2,751 \\
\text { OLS }\end{array}$ & $\begin{array}{l}0.020 \\
24 \\
49 \\
123 \\
4,815 \\
\text { IV }\end{array}$ & $\begin{array}{l}0.020 \\
24 \\
49 \\
123 \\
4,815 \\
\text { IV }\end{array}$ & $\begin{array}{l}0.077 \\
24 \\
49 \\
123 \\
5,079 \\
\text { OLS }\end{array}$ \\
\hline $\begin{array}{l}\text { Sample } \\
\text { restriction }\end{array}$ & & & $\begin{array}{l}\text { No ETC } \\
\text { discount }\end{array}$ & $\begin{array}{l}\text { No ETC } \\
\text { discount }\end{array}$ & & & \\
\hline
\end{tabular}

Note: Table reports the results of estimating variants of equation (2). All regressions include year fixed effects (not shown). All other regressors are indicated in the table; column headings define the dependent variable; the bottom two rows provide additional information on the estimation technique and sample restriction. For the IV estimation in column (5), $\triangle$ ETCYear $_{\text {it }}$ is used as an instrument for $\triangle$ ETC_Penetration $_{\text {it. }}$ For the IV estimation in column (6), a

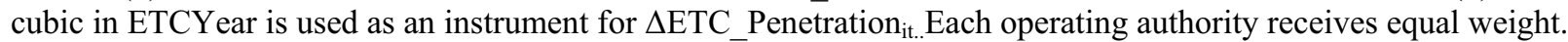
Standard errors (in parentheses) are clustered by state. P-values are reported [in square brackets]. $\Delta \mathrm{ETC}_{\mathrm{it}}$ is an indicator variable for whether facility $i$ adopted ETC in year $t . \triangle$ ETCYear $_{i t}$ is an indicator variable for whether the number of years the facility has had ETC increases by 1 ; it is zero in any year the facility does not have ETC, 1 the year the facility adopts ETC, 2 the second year the facility has ETC and so forth. $\triangle$ ETC_Penetration ${ }_{\text {it }}$ measures the change in the proportion of tolls on the facility paid by ETC; it is zero if the facility does not have ETC, and has an average value of 0.05 in years in which the facility has ETC. "No ETC discounts" limits facilities to those that never off an ETC discount. Declines in sample size in column 4 (compared to column 3) and in column 5 or 6 (compared to column 1) reflects missing data on ETC penetration rates (see Section 3.2.1). 


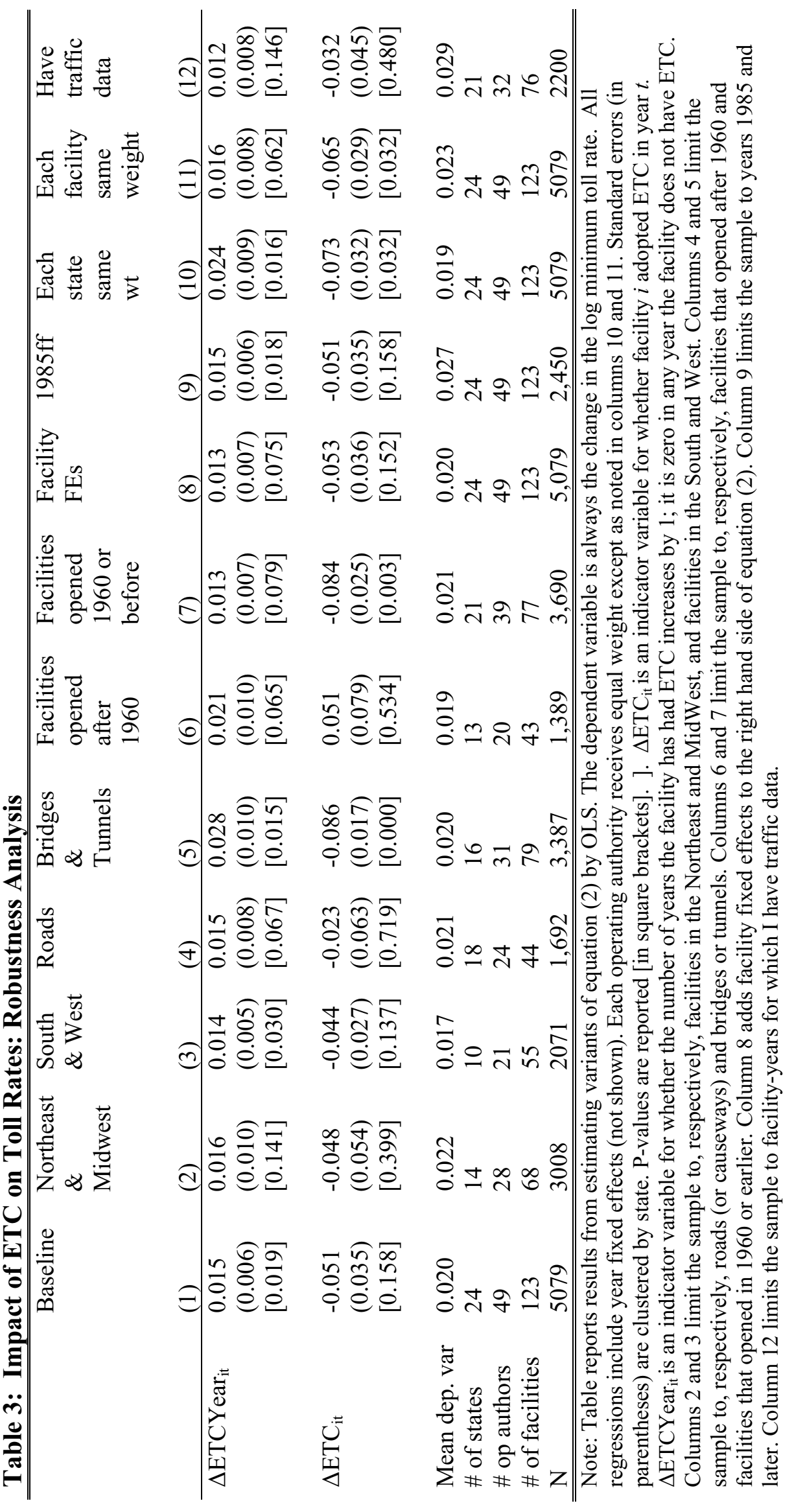


Table 4: The elasticity of traffic with respect to tolls

\begin{tabular}{|c|c|c|c|c|c|c|}
\hline & (1) & (2) & (3) & (4) & (5) & (6) \\
\hline$\Delta \log \min$. toll $_{\text {it }}$ & $\begin{array}{l}-0.049 \\
(0.015) \\
{[0.004]}\end{array}$ & $\begin{array}{l}-0.050 \\
(0.018) \\
{[0.012]}\end{array}$ & $\begin{array}{l}-0.057 \\
(0.017) \\
{[0.006]}\end{array}$ & $\begin{array}{l}-0.061 \\
(0.019) \\
{[0.009]}\end{array}$ & $\begin{array}{l}-0.060 \\
(0.037) \\
{[0.135]}\end{array}$ & $\begin{array}{l}-0.062 \\
(0.039) \\
{[0.145]}\end{array}$ \\
\hline $\begin{array}{l}\Delta \log \min _{.} \text {toll }_{\text {it }} * \\
\text { ETCYear }_{\text {it }}\end{array}$ & & $\begin{array}{l}0.002 \\
(0.002) \\
{[0.207]}\end{array}$ & $\begin{array}{l}0.006 \\
(0.001) \\
{[0.002]}\end{array}$ & & $\begin{array}{l}0.006 \\
(0.003) \\
{[0.062]}\end{array}$ & \\
\hline $\begin{array}{l}\Delta \log \min . \text { toll }_{\text {it }} * \\
\text { ETC_Penetration }_{\text {it }}\end{array}$ & & & & $\begin{array}{l}0.134 \\
(0.038) \\
{[0.005]}\end{array}$ & & $\begin{array}{l}0.141 \\
(0.076) \\
{[0.091]}\end{array}$ \\
\hline $\begin{array}{l}\Delta \log \min . \text { toll }_{\text {it }} * \\
\text { Never_ETC }\end{array}$ & & $\begin{array}{l}-0.069 \\
(0.114) \\
{[0.556]}\end{array}$ & $\begin{array}{l}-0.073 \\
(0.131) \\
{[0.588]}\end{array}$ & $\begin{array}{l}-0.071 \\
(0.136) \\
{[0.611]}\end{array}$ & $\begin{array}{l}-0.006 \\
(0.205) \\
{[0.976]}\end{array}$ & $\begin{array}{l}-0.009 \\
(0.209) \\
{[0.966]}\end{array}$ \\
\hline $\begin{array}{l}\text { Mean dep. Var } \\
\# \text { of states } \\
\# \text { op authors } \\
\# \text { of facilities } \\
\mathrm{N}\end{array}$ & $\begin{array}{l}0.049 \\
21 \\
32 \\
76 \\
2,200\end{array}$ & $\begin{array}{l}0.050 \\
21 \\
32 \\
76 \\
2,200\end{array}$ & $\begin{array}{l}0.042 \\
12 \\
16 \\
33 \\
727\end{array}$ & $\begin{array}{l}0.043 \\
12 \\
16 \\
33 \\
671\end{array}$ & $\begin{array}{l}0.039 \\
12 \\
16 \\
33 \\
305\end{array}$ & $\begin{array}{l}0.040 \\
12 \\
16 \\
33 \\
292\end{array}$ \\
\hline \multirow[t]{2}{*}{$\begin{array}{l}\text { Sample } \\
\text { restriction(s) }\end{array}$} & & & $\begin{array}{l}\text { No ETC } \\
\text { discounts }\end{array}$ & $\begin{array}{l}\text { No ETC } \\
\text { discounts }\end{array}$ & $\begin{array}{l}\text { No ETC } \\
\text { discounts }\end{array}$ & $\begin{array}{l}\text { No ETC } \\
\text { discounts }\end{array}$ \\
\hline & & & & & $\begin{array}{l}+2 /-2 \\
\text { sample }\end{array}$ & $\begin{array}{l}+2 /-2 \\
\text { sample }\end{array}$ \\
\hline
\end{tabular}

Note: Table reports results from estimating variants of equation (3) by OLS. The dependent variable is the change in log traffic. All regressions include year fixed effects as well as a main effect for any variable interactions with $\Delta \log (\min$. toll). The bottom row indicates any sample restrictions. "No ETC discounts" limits facilities to those that never off an ETC discount. " $+2 /-2$ sample" limits sample to facility-years in which there is a toll change or the 2 years before or after a facility's toll change. Never_ETC $\mathrm{E}_{\mathrm{i}}$ is an indicator variable for whether facility $i$ never has ETC. ETCYear ${ }_{i t}$ is the number of years the facility has had ETC; it is zero in any year in which the facility does not have ETC. ETC_Penetration ${ }_{\mathrm{it}}$ is the share of tolls paid by ETC on facility $i$ in year $t$; it is zero in years in which the facility does not have ETC. Each operating authority receives equal weight. Standard errors (in parentheses) are clustered by state. P-values are reported [in square brackets]. 
Table 5: The impact of ETC-induced reductions in compliance costs on toll rates

\begin{tabular}{|c|c|c|c|c|}
\hline & $(1)$ & (2) & (3) & $(4)$ \\
\hline \multirow[t]{3}{*}{$\Delta$ ETCYear $_{\text {it }}$} & 0.015 & 0.023 & 0.024 & 0.029 \\
\hline & {$[0.008]$} & $(0.011)$ & $(0.011)$ & $(0.013)$ \\
\hline & $(0.067]$ & {$[0.043]$} & {$[0.048]$} & {$[0.046]$} \\
\hline \multirow{3}{*}{$\begin{array}{l}\Delta \text { ETCYear }_{\text {it }} \\
* \text { (Measure_of_compliance_costs) }\end{array}$} & & -0.004 & -0.008 & -0.132 \\
\hline & & $(0.002)$ & (0.004) & [0.047] \\
\hline & & {$[0.122]$} & {$[0.057]$} & {$[0.013]$} \\
\hline \multirow{3}{*}{$\Delta \mathrm{ETC}_{\mathrm{it}}$} & -0.023 & -0.047 & 0.016 & 0.009 \\
\hline & $(0.063)$ & $(0.083)$ & $(0.044)$ & $(0.078)$ \\
\hline & {$[0.719]$} & {$[0.575]$} & {$[0.716]$} & {$[0.905]$} \\
\hline \multirow{3}{*}{$\begin{array}{l}\Delta \mathrm{ETC}_{\text {it }} \\
*(\text { Measure_of_compliance_costs })\end{array}$} & & 0.010 & -0.024 & -0.360 \\
\hline & & $(0.010)$ & $(0.025)$ & $(0.153)$ \\
\hline & & {$[0.323]$} & {$[0.340]$} & {$[0.033]$} \\
\hline \multirow[t]{3}{*}{ Measure_of_compliance_costs } & & -0.002 & -0.001 & 0.053 \\
\hline & & $(0.001)$ & $(0.003)$ & $(0.029)$ \\
\hline & & {$[0.017]$} & {$[0.806]$} & {$[0.086]$} \\
\hline Mean dep. var & \multicolumn{4}{|c|}{0.021} \\
\hline \# of states & \multicolumn{4}{|c|}{18} \\
\hline \# op authors & \multicolumn{4}{|c|}{24} \\
\hline \# of facilities & \multicolumn{4}{|c|}{44} \\
\hline $\mathrm{N}$ & \multicolumn{4}{|c|}{1,692} \\
\hline \multirow{2}{*}{\multicolumn{2}{|c|}{ Measure_of_compliance_costs }} & Number of & Number of & Number of \\
\hline & & transactions & $\begin{array}{l}\text { transactions } \\
\text { per } \$ \text { toll }\end{array}$ & $\begin{array}{l}\text { transactions } \\
\text { per mile }\end{array}$ \\
\hline
\end{tabular}

Note: Sample limited to roads. Table reports results from estimating variants of equation (2) by OLS. The dependent variable is the change in the log minimum toll rate. All regressions include year fixed effects in addition to the regressors shown in the table. $\Delta \mathrm{ETC}_{\mathrm{it}}$ is an indicator variable for whether facility $i$ adopted ETC in year $t$. $\triangle$ ETCYear $_{i t}$ is an indicator variable for whether the number of years the facility has had ETC increases by 1 ; it is zero in any year the facility does not have ETC. The "Measure_of_compliance_costs" variable is defined differently across the columns. In column 2 is denotes the number of separate toll transactions that someone driving a full length trip on the road must make; it is defined in 1985. In column 3 it is defined as the number of separate toll transactions divided by the monetary toll paid for a full length trip; both numerator and denominator are defined in 1985. In column 4 it denotes the number of separate toll transactions divided by the mileage for a full length trip; both numerator and denominate or defined in 1985. Each operating authority receives equal weight. Standard errors (in parentheses) are clustered by state. P-values are reported [in square brackets]. 
Table 6: Impact of Changing from Two-Way to One-Way Tolling on Tolls

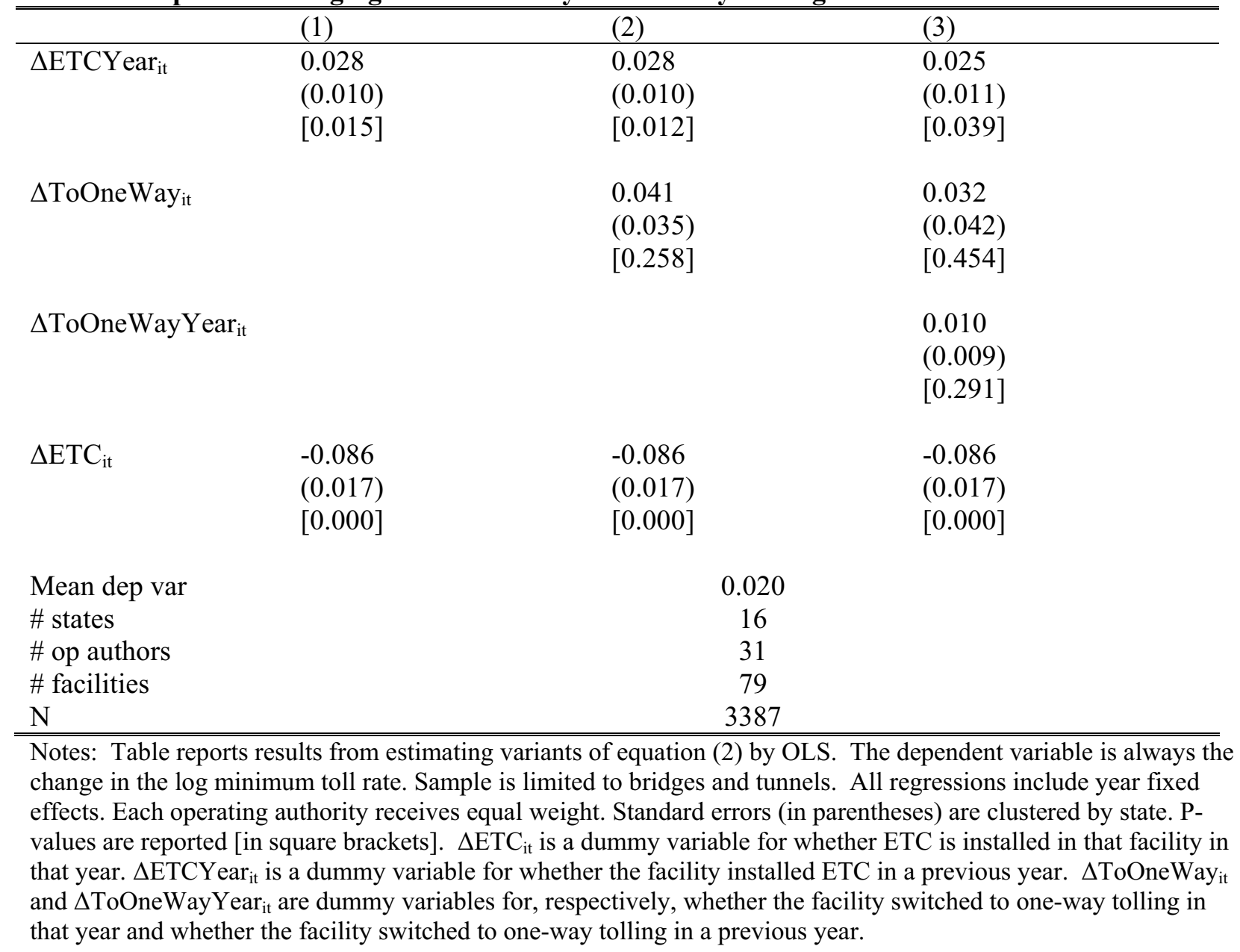


Table 7: Changes in traffic, revenue and tolls prior to ETC adoption.

\begin{tabular}{|c|c|c|c|c|c|c|}
\hline & \multicolumn{2}{|c|}{$\begin{array}{c}\text { Dep Var: } \\
\Delta \log (\text { traffic })\end{array}$} & \multicolumn{2}{|c|}{$\begin{array}{c}\text { Dep Var: } \\
\Delta \log (\text { revenue })\end{array}$} & \multicolumn{2}{|c|}{$\begin{array}{c}\text { Dep Var: } \\
\Delta \log (\text { minimum toll })\end{array}$} \\
\hline & (1) & (2) & (3) & (4) & $(5)$ & (6) \\
\hline $1-2$ years before & -0.000 & & -0.009 & & 0.004 & \\
\hline \multirow[t]{2}{*}{ ETCAdopted } & $(0.007)$ & & $(0.016)$ & & $(0.013)$ & \\
\hline & [0.955] & & {$[0.599]$} & & {$[0.777]$} & \\
\hline \multirow{3}{*}{$\begin{array}{l}1-5 \text { years before } \\
\text { ETCAdopted }\end{array}$} & & 0.013 & & 0.006 & & 0.009 \\
\hline & & $(0.010)$ & & $(0.012)$ & & $(0.007)$ \\
\hline & & [0.198] & & [0.601] & & {$[0.242]$} \\
\hline \multirow[t]{3}{*}{$\Delta \mathrm{ETC}_{\mathrm{it}}$} & -0.000 & 0.000 & 0.002 & 0.002 & -0.051 & -0.051 \\
\hline & $(0.010)$ & $(0.010)$ & $(0.025)$ & $(0.025)$ & $(0.035)$ & $(0.035)$ \\
\hline & [0.996] & [0.978] & {$[0.922]$} & [0.930] & {$[0.158]$} & {$[0.162]$} \\
\hline \multirow[t]{3}{*}{$\Delta$ ETCYear $_{\text {it }}$} & -0.006 & -0.001 & 0.028 & 0.031 & 0.016 & 0.017 \\
\hline & $(0.010)$ & $(0.010)$ & $(0.015)$ & $(0.015)$ & $(0.006)$ & $(0.006)$ \\
\hline & [0.551] & [0.959] & {$[0.090]$} & {$[0.058]$} & [0.018] & [0.008] \\
\hline Mean dep. Var & \multicolumn{2}{|c|}{0.049} & \multicolumn{2}{|c|}{0.077} & \multicolumn{2}{|c|}{0.020} \\
\hline \# of states & \multicolumn{2}{|c|}{21} & \multicolumn{2}{|c|}{13} & \multicolumn{2}{|c|}{24} \\
\hline \# op authors & \multicolumn{2}{|c|}{32} & \multicolumn{2}{|c|}{19} & \multicolumn{2}{|c|}{49} \\
\hline \# of facilities & \multicolumn{2}{|c|}{76} & \multicolumn{2}{|c|}{45} & \multicolumn{2}{|c|}{123} \\
\hline $\mathrm{N}$ & \multicolumn{2}{|c|}{2,200} & \multicolumn{2}{|c|}{1,411} & \multicolumn{2}{|c|}{5,079} \\
\hline
\end{tabular}

Note: Table reports results from estimating variants of equation (2) by OLS. Dependent variables are defined in the column headings. All regressions include year fixed effects. Each operating authority receives equal weight.

Standard errors (in parentheses) are clustered by state. P-values are reported [in square brackets]. "1-2 years before ETCAdoptedt" is an indicator variable for whether it is one to two years before the facility adopts ETC. "1-5 years before ETCAdopted" is an indicator variable for whether it is one to five years before the facility adopts ETC. $\triangle \mathrm{ETC}_{\mathrm{it}}$ is a dummy variable for whether ETC is installed in that facility in that year. $\triangle \mathrm{ETCYear}_{\mathrm{it}}$ is a dummy variable for whether the facility installed ETC in a previous year. 


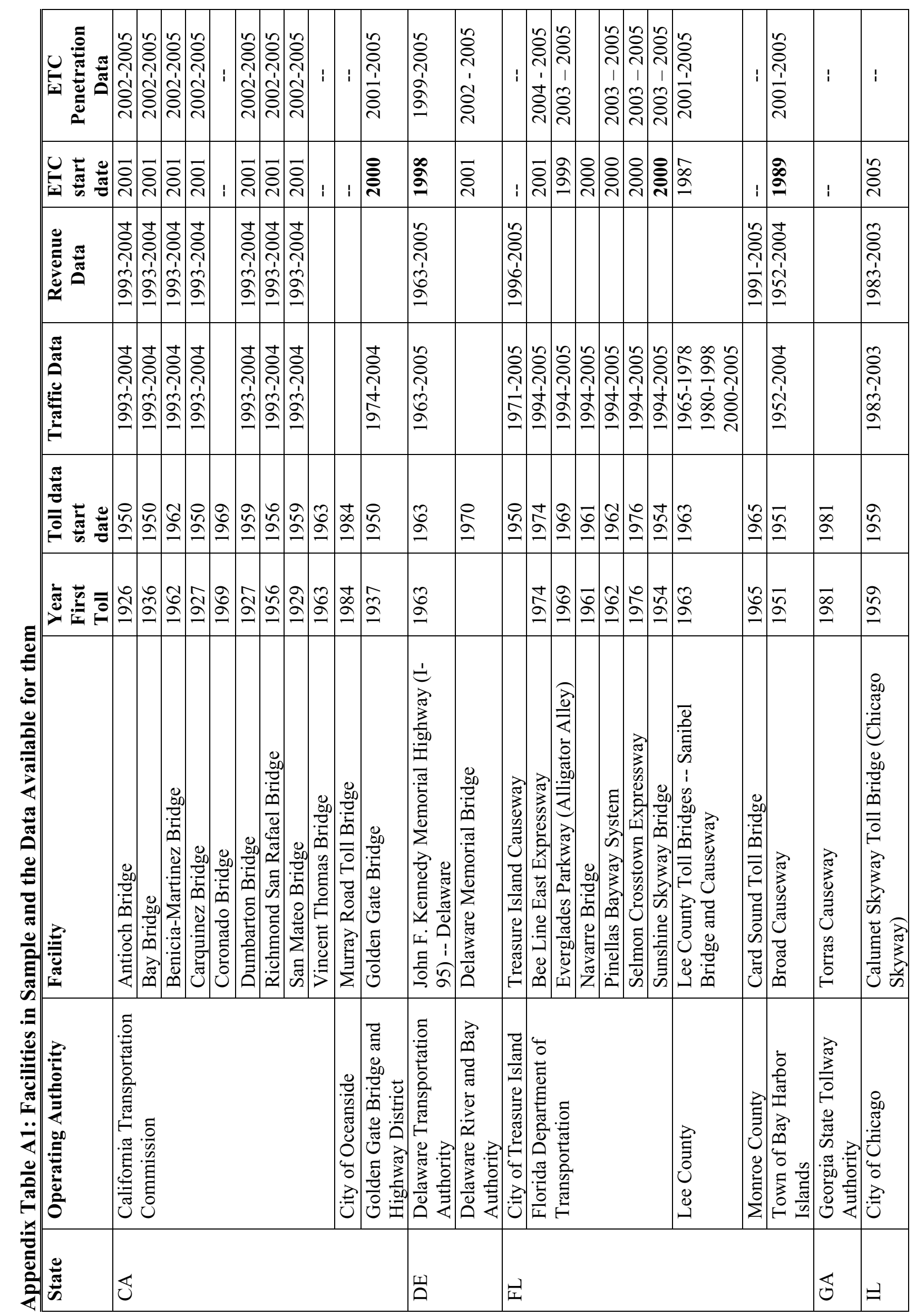




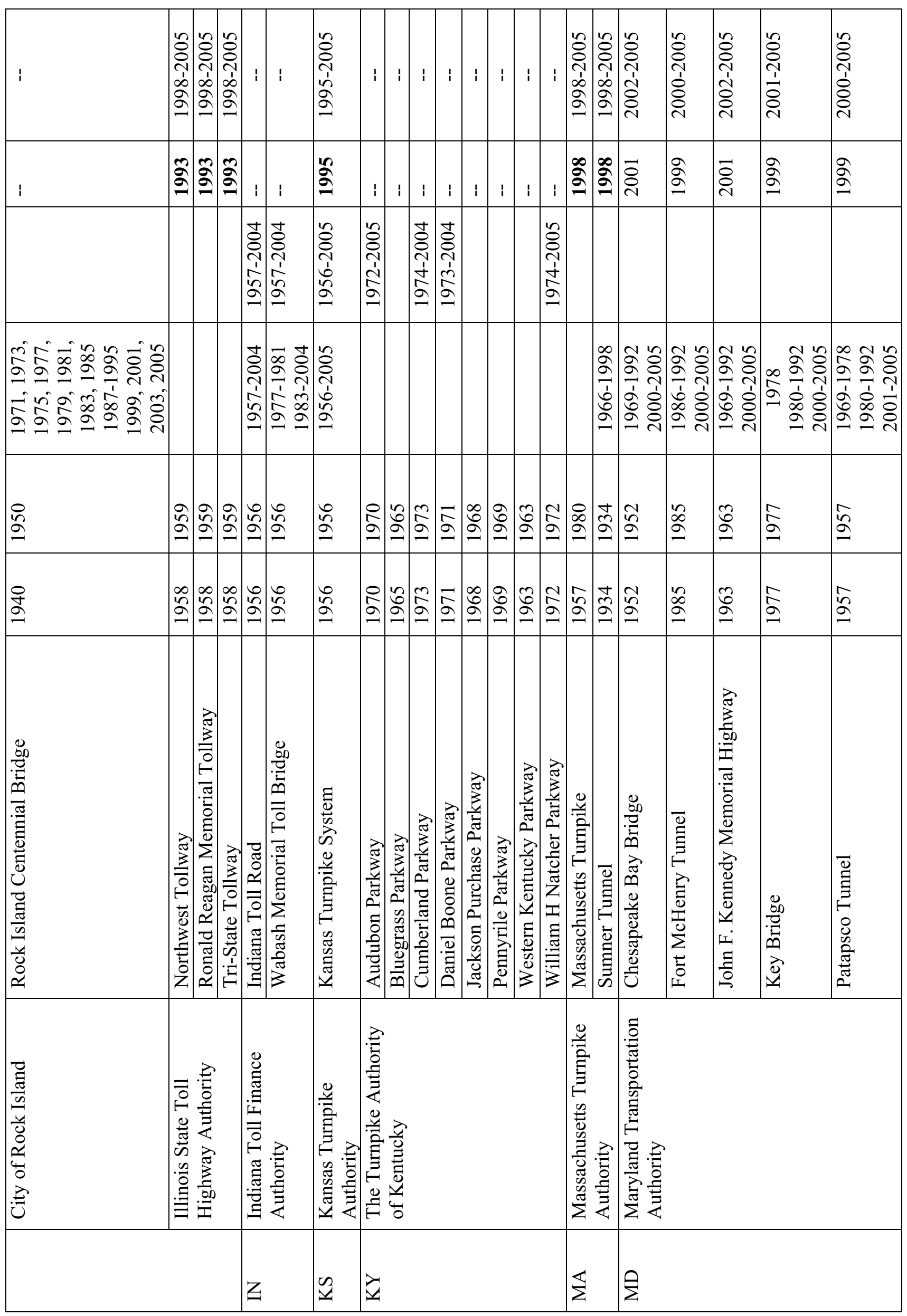




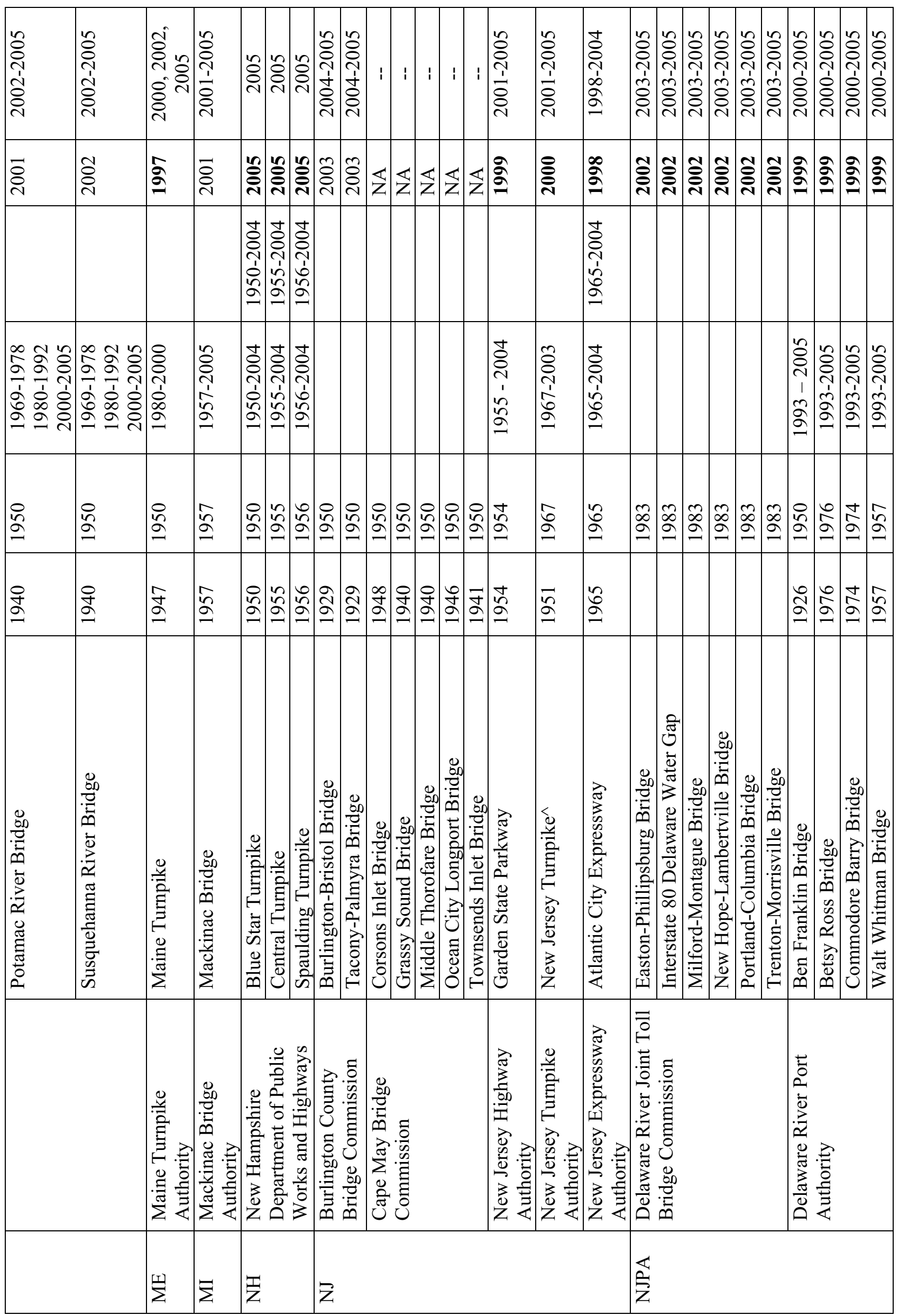




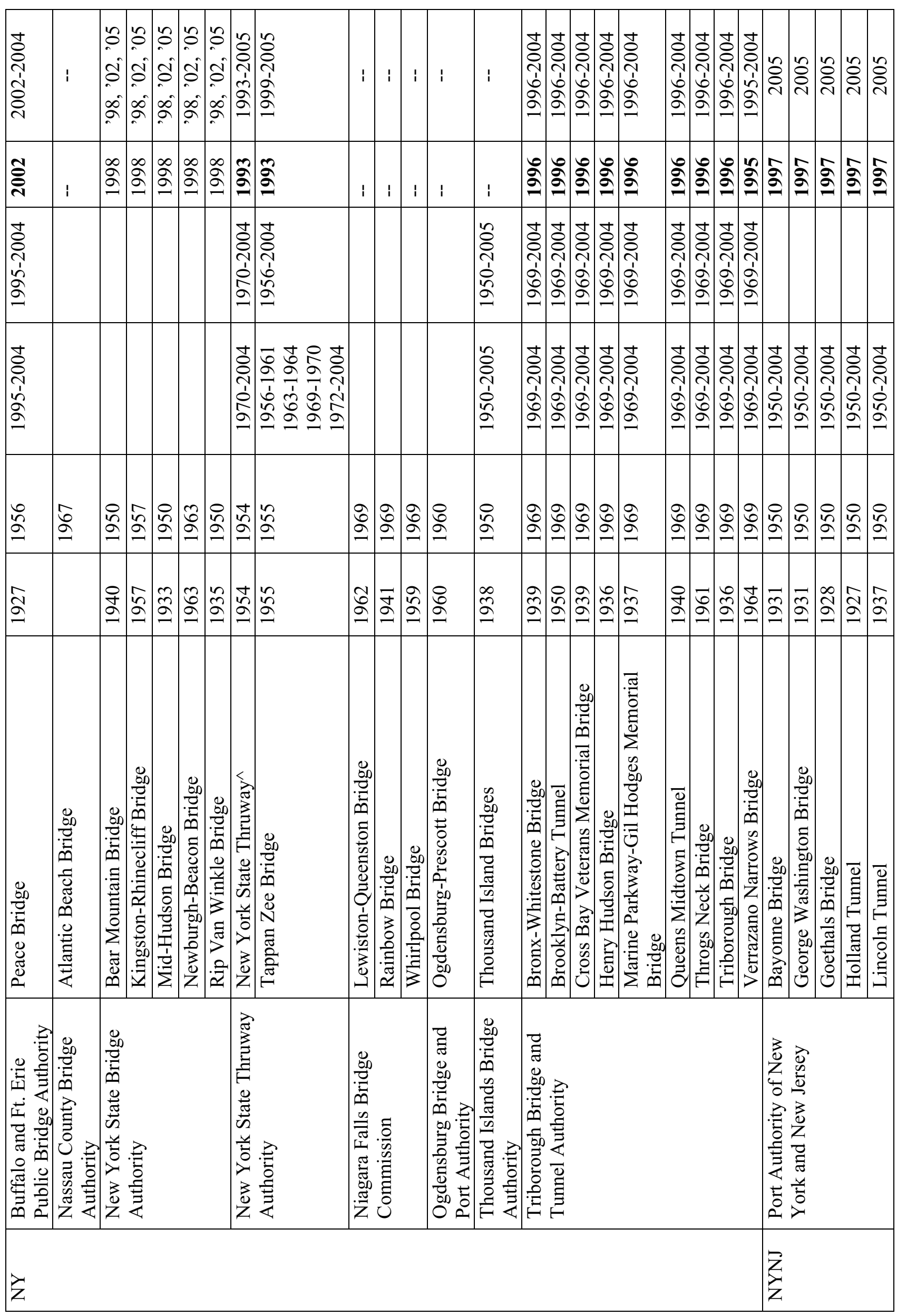




\begin{tabular}{|c|c|c|c|c|c|c|c|c|c|c|c|c|c|c|c|c|c|c|}
\hline 8 & i & 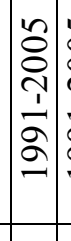 & 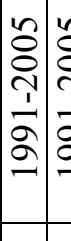 & 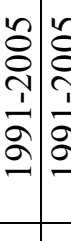 & 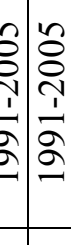 & $\mid \begin{array}{l}2 \\
8 \\
0 \\
1 \\
1 \\
2 \\
2\end{array}$ & i & 1 & I & & 1 & $1 \mid \begin{array}{l}y \\
\S \\
\varepsilon\end{array}$ & 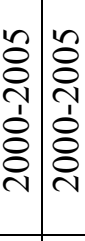 & 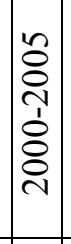 & 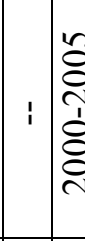 & 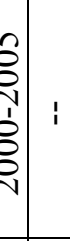 & & 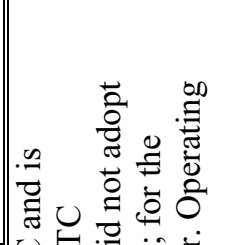 \\
\hline 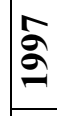 & 1 & $\bar{\sigma}$ & $\bar{\sigma}$ & $\bar{\sigma}$ & 2 & $\bar{\sigma}$ & I & 1 & i & ஓ & i i & & बे & बे & i & 2.: & 离 & 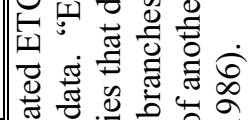 \\
\hline & 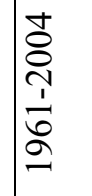 & 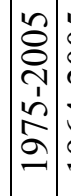 & 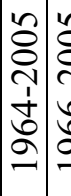 & 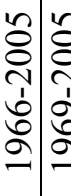 & 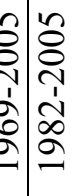 & $\mid \begin{array}{l}n \\
0 \\
0 \\
1 \\
1 \\
2 \\
2 \\
1\end{array}$ & & & 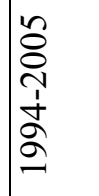 & & & & & & & & & 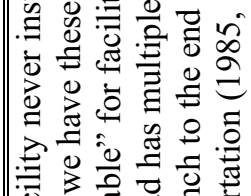 \\
\hline 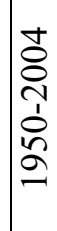 & 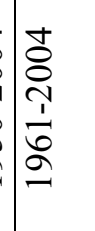 & 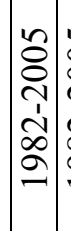 & 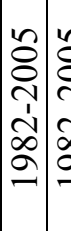 & 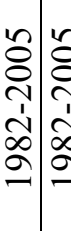 & 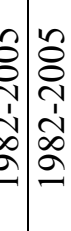 & $\left|\begin{array}{l}n \\
\delta \\
0 \\
1 \\
1 \\
\tilde{0} \\
0 \\
0\end{array}\right|$ & & & 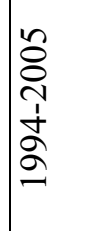 & 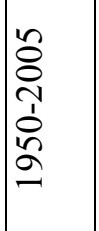 & & & 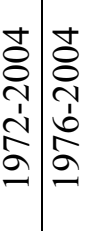 & $\left|\begin{array}{l} \pm \\
8 \\
0 \\
1 \\
\\
\hat{\sigma}\end{array}\right|$ & 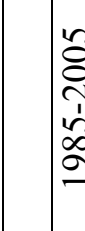 & 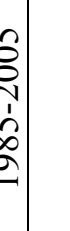 & $\begin{array}{l}n \\
8 \\
0 \\
1 \\
\\
2 \\
2\end{array}$ & 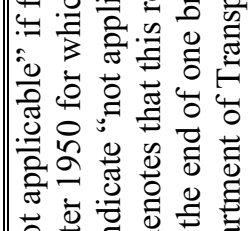 \\
\hline$\stackrel{2}{2}$ & 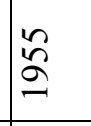 & 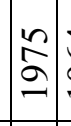 & 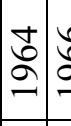 & \begin{tabular}{l|l}
0 \\
0 \\
2 & 0 \\
\hdashline & 0 \\
\end{tabular} & 2ิ|ñ & $\hat{n}$ & \begin{tabular}{l}
8 \\
$\vdots$ \\
\hdashline
\end{tabular} & $\stackrel{2}{2}$ & $\stackrel{2}{2}$ & 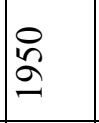 & \begin{tabular}{l|l}
0 & $n$ \\
0 & 2 \\
2 & 0 \\
\end{tabular} & 2 & \begin{tabular}{l|l}
0 \\
ลे \\
2 \\
2
\end{tabular} & $\stackrel{m}{a}$ & $\begin{array}{l}\hat{\sigma} \\
2 \\
2\end{array}$ & 2) & $\stackrel{4}{2}$ & 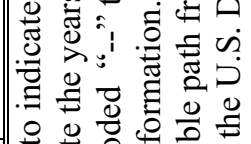 \\
\hline$\stackrel{\infty}{\Omega}$ & $\tilde{n}$ & 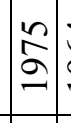 & \begin{tabular}{|l|l} 
\\
0 \\
0 \\
-1 & 0 \\
\end{tabular} & $\begin{array}{lll}0 & 8 \\
0 & 0\end{array}$ & 2ิ| & $\hat{2}$ & $\begin{array}{l}8 \\
\stackrel{0}{2}\end{array}$ & 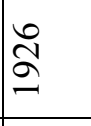 & 売 & \& & \begin{tabular}{l|l}
$\hat{\sigma}$ & \multicolumn{1}{c}{} \\
0 & 0 \\
- & 0
\end{tabular} & 2 & \begin{tabular}{l|l}
6 \\
2ิ \\
2
\end{tabular} & $\stackrel{m}{a}$ & $\mid \begin{array}{l}\hat{6} \\
2 \\
2\end{array}$ & \begin{tabular}{l}
\multirow{2}{*}{$\infty$} \\
2 \\
2 \\
2
\end{tabular} & 点 & 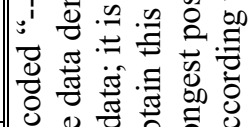 \\
\hline 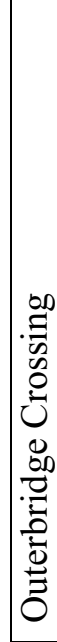 & 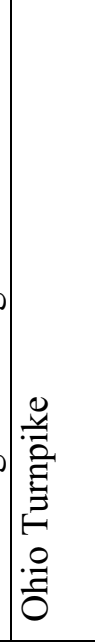 & 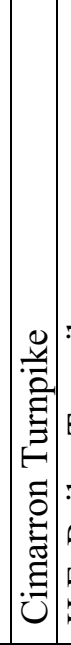 & 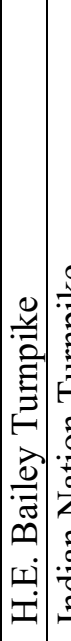 & 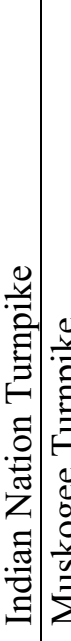 & 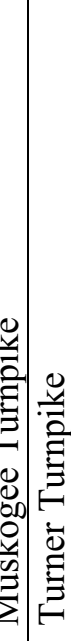 & 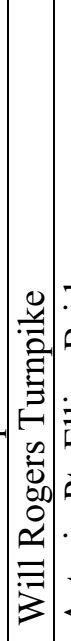 & 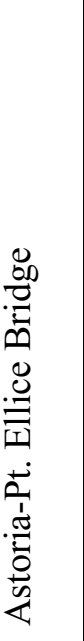 & 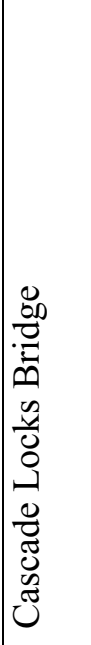 & 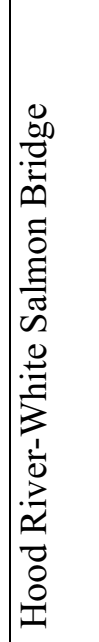 & 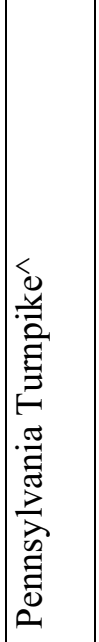 & 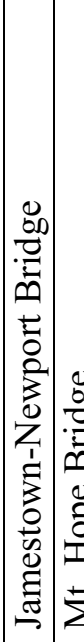 & 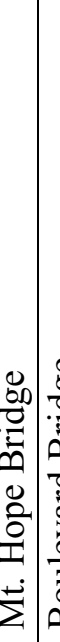 & 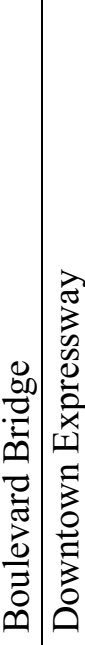 & 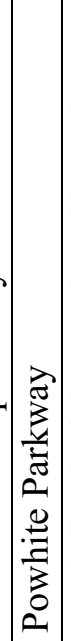 & 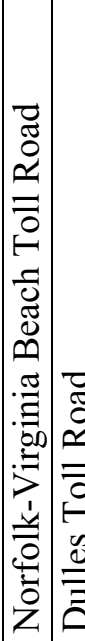 & 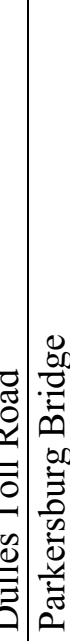 & 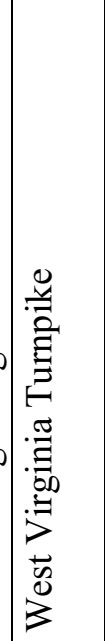 & 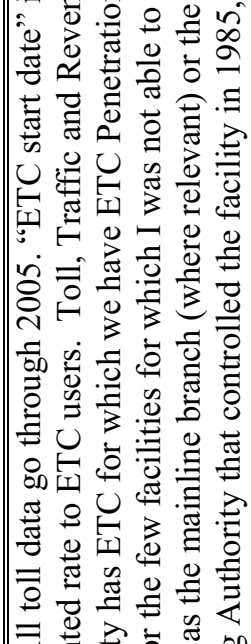 \\
\hline & 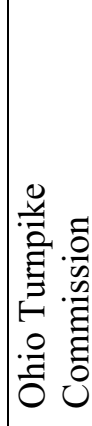 & 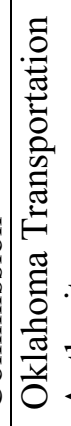 & & & & & 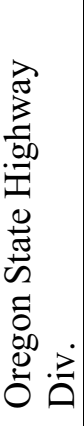 & 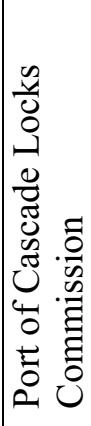 & 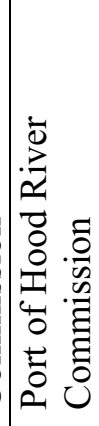 & 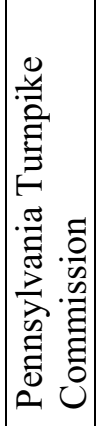 & 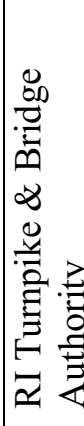 & & 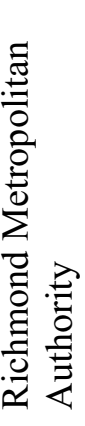 & & 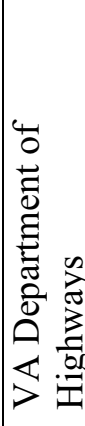 & 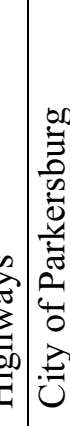 & 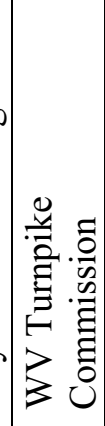 & 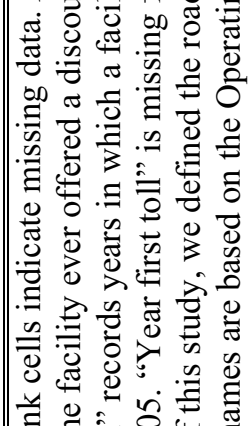 \\
\hline & $\overline{0}$ & $\frac{y}{0}$ & & & & & 0 & & & & $\Omega$ & & $\stackrel{\$}{>}$ & & & 3 & & 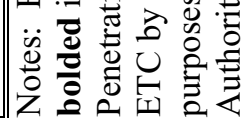 \\
\hline
\end{tabular}


Table A2: Target facilities lacking requisite data for analysis

\begin{tabular}{|c|c|c|c|}
\hline State & Operating Authority & Facility & $\begin{array}{l}\text { Toll in } \\
\text { 2003? }\end{array}$ \\
\hline $\mathrm{CO}$ & City of Colorado Springs & Pikes Peak Toll Highway & 1 \\
\hline \multirow[t]{7}{*}{ CT } & \multirow[t]{7}{*}{ Connecticut Department of Transportation } & Charter Oak Bridge & 0 \\
\hline & & Connecticut Turnpike & 0 \\
\hline & & John Bissell Bridge & 0 \\
\hline & & Merritt Parkway & 0 \\
\hline & & Thames River Bridge & 0 \\
\hline & & Wilbur Cross Parkway & 0 \\
\hline & & William H. Putnam Bridge & 0 \\
\hline \multirow[t]{11}{*}{ FL } & City of Clearwater & Clearwater Toll Bridge & 0 \\
\hline & \multirow{2}{*}{ Dade County Port Authority } & Biscayne Key (Rickenbacker) Causeway & 1 \\
\hline & & Venetian Causeway & 1 \\
\hline & Escambia County & Pensacola Beach Bridge & 1 \\
\hline & \multirow{5}{*}{ Florida Department of Transportation } & Central Florida Expressway & 1 \\
\hline & & Florida Turnpike System* & 1 \\
\hline & & Miami-Dade County Expressways & 1 \\
\hline & & St. George Island (Bryant Patton) Bridge & 0 \\
\hline & & $\begin{array}{l}\text { Tampa-Hillsborough County (South } \\
\text { Crosstown) Expressway }\end{array}$ & 1 \\
\hline & Jacksonville Transportation Authority & Jacksonville Expressway System & 0 \\
\hline & Ocean Highway and Port Authority & Buccaneer Trail Road & 0 \\
\hline \multirow[t]{6}{*}{ IA } & City of Burlington & MacArthur (Burlington) Bridge & 0 \\
\hline & City of Keokuk & Keokuk Municipal Bridge & 0 \\
\hline & \multirow{4}{*}{ Iowa Department of Transportation } & Clinton Toll Bridge & 0 \\
\hline & & Dubuque Toll Bridge & 0 \\
\hline & & Muscatine Bridge & 0 \\
\hline & & Savanna-Sabula Toll Bridge & 0 \\
\hline \multirow[t]{4}{*}{$\mathrm{IL}$} & City of Chester & Chester (Mississippi River) Bridge & 0 \\
\hline & City of East St. Louis & $\begin{array}{l}\text { Martin Luther King (Veterans Memorial) } \\
\text { Bridge }\end{array}$ & 0 \\
\hline & City of Venice & McKinley Bridge & 0 \\
\hline & White County Bridge Commission & New Harmony Bridge & 1 \\
\hline \multirow[t]{2}{*}{ IN } & Indiana Toll Finance Authority & Hawesville-Cannelton Bridge & 0 \\
\hline & Indiana Transportation Finance Authority & Brandenburg-Maukport Bridge & 1 \\
\hline$\overline{\mathrm{LA}}$ & Greater New Orleans Expressway Commission & Greater New Orleans Expressway & 1 \\
\hline MA & Massachusetts Port Authority & Maurice J. Tobin (Mystic River) Bridge & 1 \\
\hline \multirow[t]{2}{*}{ MI } & International Bridge Authority of MI & Sault Sainte Marie Bridge & 1 \\
\hline & Michigan Department of Transportation & Blue Water Bridge & 1 \\
\hline $\mathrm{MN}$ & Village of Baudette & $\begin{array}{l}\text { Baudette-Rainy River International } \\
\text { Bridge }\end{array}$ & 0 \\
\hline \multirow[t]{3}{*}{$\mathrm{MO}$} & City of Kansas City & Broadway Bridge & 0 \\
\hline & Platte County & Platte Purchase Bridge & 0 \\
\hline & Wayland Special Road District & St. Francisville Bridge & 1 \\
\hline \multirow[t]{2}{*}{$\mathrm{NE}$} & Bellevue Bridge Commission & Bellevue Bridge & 1 \\
\hline & Burt County Bridge Commission & $\begin{array}{l}\text { Burt County Missouri River (Decatur) } \\
\text { Bridge }\end{array}$ & 1 \\
\hline NY & Lake Champlain Bridge Commission & Crown Point Bridge & 0 \\
\hline
\end{tabular}




\begin{tabular}{|l|l|l|c|}
\hline \multirow{4}{*}{ TX } & Cameron County & Rouses Point Bridge & 0 \\
\cline { 2 - 4 } & City of Del Rio & $\begin{array}{l}\text { Cameron County International Toll } \\
\text { Bridge }\end{array}$ & 1 \\
\cline { 2 - 4 } & City of Eagle Pass & Del Rio International Bridge & 1 \\
\cline { 2 - 4 } & City of El Paso & $\begin{array}{l}\text { Eagle Pass-Piedras Negras International } \\
\text { Bridge }\end{array}$ & 1 \\
\cline { 2 - 4 } & City of Laredo & El Paso International Bridge & 1 \\
\cline { 2 - 4 } & City of McAllen & Laredo-Nuevo Laredo International & 1 \\
\cline { 2 - 4 } & Galveston County & Bridge & 1 \\
\cline { 2 - 4 } & Harris County Toll Road Authority & McAllen International Toll Bridge & 1 \\
\cline { 2 - 4 } & Starr County & San Luis Pass-Vacek Bridge & 1 \\
\cline { 2 - 4 } & Texas Turnpike Authority & Harris County Toll Road & 0 \\
\hline \multirow{5}{*}{ VA } & Chesapeake Bay Bridge and Tunnel District & Roma International Toll Bridge & 1 \\
\cline { 2 - 4 } & & Dallas North Tollway & 1 \\
\cline { 2 - 4 } & City of Chesapeake & Houston Ship Channel Bridge & 0 \\
\cline { 2 - 4 } & Virginia Department of Highways & Sountain Creek Lake Bridge & 0 \\
\hline
\end{tabular}

Note: Last column indicates whether or not facility is still charging toll in 2003; this is based on data from U.S. Department of Transportation $(2003,2004)$. These were the latest available data as of August 2006. * Denotes that facility provided dates of toll changes, but not actual toll rates. 